\title{
Korean clinical practice guideline for perioperative red blood cell transfusion from Korean Society of Anesthesiologists
}

\author{
Bon-Nyeo Koo ${ }^{1}$, Min A Kwon², Sang-Hyun Kim³, Jong Yeop Kim, \\ Young-Jin Moon ${ }^{5}$, Sun Young Park ${ }^{6}$, Eun-Ho Lee ${ }^{5}$, Min Suk Chae $^{7}$, \\ Sung Uk Choi ${ }^{8}$, Jeong-Hyun Choi ${ }^{9}$, and Jin-Young Hwang ${ }^{10}$ \\ Department of Anesthesiology and Pain Medicine, ${ }^{1}$ Yonsei University College of Medicine, Seoul, ${ }^{2}$ Dankook \\ University Hospital, Cheonan, ${ }^{3}$ Soonchunhyang University Bucheon Hospital, Soonchunhyang University College of \\ Medicine, Bucheon, ${ }^{4}$ Ajou University School of Medicine, Suwon, ${ }^{5}$ Asan Medical Center, University of Ulsan College \\ of Medicine, Seoul, ${ }^{6}$ Soonchunhyang University Seoul Hospital, Soonchunhyang University College of Medicine, \\ Seoul, ${ }^{7}$ Seoul St. Mary's Hospital, College of Medicine, The Catholic University of Korea, Seoul, ${ }^{8}$ Korea University \\ College of Medicine, Seoul, ${ }^{9}$ Kyung Hee University College of Medicine, Seoul, ${ }^{10}$ SMG-SNU Boramae Medical \\ Center, Seoul National University College of Medicine, Seoul, Korea
}

Background: Considering the functional role of red blood cells (RBC) in maintaining oxygen supply to tissues, RBC transfusion can be a life-saving intervention in situations of severe bleeding or anemia. RBC transfusion is often inevitable to address intraoperative massive bleeding; it is a key component in safe perioperative patient management. Unlike general medical resources, packed RBCs (pRBCs) have limited availability because their supply relies entirely on voluntary donations. Additionally, excessive utilization of pRBCs may aggravate prognosis or increase the risk of developing infectious diseases. Appropriate perioperative RBC transfusion is, therefore, crucial for the management of patient safety and medical resource conservation. These concerns motivated us to develop the present clinical practice guideline for evidence-based efficient and safe perioperative RBC transfusion management considering the current clinical landscape. Methods: This guideline was obtained after the revision and refinement of exemplary clinical practice guidelines developed in advanced countries. This was followed by rigorous evidence-based reassessment considering the healthcare environment of the country. Results: This guideline covers all important aspects of perioperative RBC transfusion, such as preoperative anemia management, appropriate RBC storage period, and leukoreduction (removal of white blood cells using filters), reversal of perioperative bleeding tendency, strategies for perioperative RBC transfusion, appropriate blood management protocols, efforts to reduce blood transfusion requirements, and patient monitoring during a perioperative transfusion.

Conclusions: This guideline will aid decisions related to RBC transfusion in healthcare settings and minimize patient risk associated with unnecessary $\mathrm{pRBC}$ transfusion.

Keywords: Blood transfusion; Clinical practice guideline; Perioperative management; Red blood cells.

Corresponding author: Eun-Ho Lee, M.D., Ph.D.

Department of Anesthesiology and Pain Medicine, Asan Medical Center, University of Ulsan College of Medicine, 88 Olympic-ro 43-gil, Songpagu, Seoul 05505, Korea

Tel: 82-2-3010-3888, Fax: 82-2-470-1363, Email: leho@naver.com

ORCID: https://orcid.org/0000-0002-6369-7429

Received: November 19, 2018. Accepted: November 27, 2018.

Korean J Anesthesiol 2019 April 72(2): 91-118

https://doi.org/10.4097/kja.d.18.00322

(c) This is an open-access article distributed under the terms of the Creative Commons Attribution Non-Commercial License (http://creativecommons.org/ licenses/by-nc/4.0/), which permits unrestricted non-commercial use, distribution, and reproduction in any medium, provided the original work is properly cited. 


\section{Introduction}

Red blood cells (RBC) play a crucial role in supplying oxygen to the tissues. In patients with acute bleeding or anemia, RBC transfusion is a life-saving intervention [1]. Each year, approximately 2 million units of packed RBCs (pRBCs) are used in Korea [2], of which $30 \%-40 \%$ are used during the perioperative period, mostly involving massive transfusion. Appropriate perioperative RBC transfusion is, therefore, crucial for the management of patient safety and medical resource. RBC transfusion is essential for treating intraoperative massive bleeding, and is, therefore, an integral part of safe perioperative patient management $[1,3]$. However, excessive use of pRBCs may aggravate a patient's prognosis or increase the risk of developing infectious diseases. Moreover, pRBCs are a limited medical resource, and their supply relies entirely on voluntary donations, unlike general medical resources. Due to this peculiarity of pRBCs, RBC transfusions are indicated only when strictly necessary and supported by evidence.

For these reasons, we developed the present evidence-based clinical practice guideline to ensure efficient and safe perioperative RBC transfusion. This guideline contains recommendations for decision-making related to RBC transfusion in clinical settings, aiming to minimize patient risk due to unnecessary $\mathrm{pRBC}$ transfusion during perioperative periods. It covers all important aspects of RBC transfusion, such as optimized hemoglobin level thresholds for RBC transfusion, restrictive preoperative and intraoperative $\mathrm{RBC}$ transfusion strategies, appropriate $\mathrm{RBC}$ storage period and leukoreduction for safe RBC transfusion, and patient monitoring during perioperative transfusion. Finally, this guideline contains items regarding the necessity of a transfusion protocol for efficient RBC transfusion tailored to the circumstances of each healthcare institution.

This guideline results from the revision and refinement of exemplary clinical practice guidelines developed and used in advanced countries, adapting the recommendations to the current clinical landscape of Korea, followed by rigorous evidence-based reassessment considering the healthcare environment of the country. We hope that this guideline will be widely used in clinical settings so that safe and optimal care can be provided when administering perioperative RBC transfusion.

\section{Methodology}

\section{Purpose and process of guideline development}

This guideline was prepared for the purpose of ensuring appropriate perioperative RBC transfusion in adult patients, and protecting them from unnecessary transfusion, and to provide strategies for efficient utilization of $\mathrm{pRBCs}$ as a limited medical resource. Guidelines for perioperative RBC transfusion have previously been developed and are used in individual countries across the world. Since these guidelines cannot be directly applied to Korea, it was necessary to develop a guideline tailored to the Korean healthcare environment. Therefore, we developed this guideline by the adaptation of guidelines, which is a method of clinical guideline development, i.e., by adapting recommendations from various related sources to the perioperative clinical environment of the country [4].

\section{Composition of guideline development group}

Three groups (i.e., Development Group, Writing Group, and Advisory Group) were convened for the development of the Korean Clinical Practice Guideline for Perioperative Red Blood Cell Transfusion (hereinafter the "Guideline").

The Development Group was mainly responsible for methodological aspects, such as planning and decision-making regarding the development of the guideline, searching and selecting existing guidelines, and preparing the overall methodology for a detailed adaptation process, including evaluation, oversight of the Writing Group, review of the development process, and preparation of distribution and implementation strategies. The Writing Group performed the adaption process through discussion and opinion sharing regarding guideline development planning, selection of key questions and keywords, review and selection of the gathered guidelines, systematic extraction of recommendations and evidence for each key question, formulation of draft recommendations, and finalization of recommendations. The Advisory Group consulted on the process of guideline development during the adaptation stage, reviewed the draft recommendations, and participated in the expert panel (Delphi technique) to finalize the recommendations. The Advisory Group was composed of anesthesiologists specializing in perioperative blood transfusion, experts from societies related to blood transfusion, and research methodologists.

\section{Overall adaptation process}

In the first phase of the adaptation process, the Development Group agreed upon on the guideline development methodology. In the early development stage, the starting members performed a systematic search of related topics. They selected the Practice Guidelines for Perioperative Blood Management (2015) issued by the American Society of Anesthesiologists (ASA) [5], reviewed the text, and decided that it would be used as a basis for the adaptation work. Concurrently, the Writing Group searched existing national and international clinical practice guidelines, evaluated all collected guidelines, and selected those to be used for the adaptation work. Next, they systematically collected the corresponding recommendations and evidence based on the predetermined key questions and evaluated the applicability of 
selected guidelines to the Korean healthcare environment. Based on the reviewed and revised recommendations and evidence, the recommendations and evidence summaries were drafted. The Advisory Group evaluated and revised the draft version using the Delphi technique. The final version of the guideline was then issued, with a level of evidence (LOE) and grade of recommendation (GOR) assigned to each added recommendation and evidence summary, followed by external review and the process of clinical practice guideline approval (Fig. 1).

\section{Search and selection of clinical practice guidelines}

A comprehensive search of all major international databases (Medline, EMBASE, Cochrane, G-I-N, AHRQ, NICE, SIGN, CMA Infobase, GAIN, WHO Guidelines, Australian Clinical Practice Guidelines, and Canadian Clinical Practice Guidelines) and Korean databases (KmBase, KoreaMed, and KoMGI) was conducted; the latter was included to reflect the Korean healthcare environment in the clinical practice guideline. The search was systematically organized-including the selection of search terms, formulation of search algorithms, and development of search strategies - and implemented through collaboration between a professional librarian experienced in the source (clinical practice guidelines) search (Jeong Eun-Ae, Medical Library of Soonchunhyang University Bucheon Hospital) and the Development Group (Appendix 1). In total, 2,354 published materials were collected and subjected to title and abstract review. The shortlisted papers were discussed during joint meetings of the Development and Writing Groups. As a result, four clinical practice guidelines were selected as the basis for the adaptation work: Practice Guidelines for Perioperative Blood Management: An Updated Report by the American Society of Anesthesiologists Development Committee on Perioperative Blood Management (2015), the Association of Anaesthetistis of Great Britain and Ireland (AAGBI) Guidelines: the use of blood components and their alternatives (2016), Clinical Practice Guidelines from the the American Association of Blood Banks (AABB) Red Blood Cell Transfusion Thresholds and Storage (2016), and the fourth edition of the Korean Transfusion Guideline (Fully revised 2016 edition) [5-7]. ${ }^{1)}$

The Writing Group evaluated the clinical practice guidelines using the assessment tool, K-AGREE II (the Korean version of the Appraisal of Guidelines for Research and Evaluation II) (Appendix 2) $[8,9]$. Three or more evaluators assessed each paper,

\footnotetext{
${ }^{1)}$ Guidelines on blood transfusion, 4th edition (complete revision in 2016). Ministry of Health and Welfare, Korea Centers for Disease Control and Prevention, Korean Society of Blood Transfusion.

Available from http://www.nih.go.kr/CDC/together/CdcKrTogether0302. jsp?menuIds=HOME001-MNU1154-MNU0004-MNU0088\&fid=51\&q type $=\&$ q_value $=\&$ cid $=70840 \&$ pageNum $=1$
}

assigning a score on a 7-point scale to each quality assessment item to ensure the reproducibility and accuracy of evaluation results; items with a score gap of four or more were re-evaluated. When guidelines were selected for recommendation and evidence extraction, those with few other relevant guidelines or those that were developed domestically were prioritized, despite having low scores.

\section{Determination of the level of evidence (LOE) and grade of recommendation (GOR)}

A modified Grading of Recommendations Assessments, Development and Evaluation (GRADE) approach was adopted to assign the LOE and GOR.

The LOE was classified into five levels (A, B, C, D, and G) for each key question (Table 1). The GOR was classified into four grades: strong recommendation (Grade I "is recommended"), weak recommendation (Grades IIa and IIb "should be recommended" and "may be recommended," respectively), and not recommended (Grade III “is not recommended") (Table 2).

Through joint discussions of the Development and Writing Groups, the GOR was assigned by comprehensively considering all related factors such as the LOE, benefit-risk, resource use, and clinical usefulness. Even when the LOE for management strategies is low, if their benefits appear to outweigh the risk, or if they are highly useful in clinical practice, the GOR was partially upgraded by a majority vote of the Development and Writing Groups.

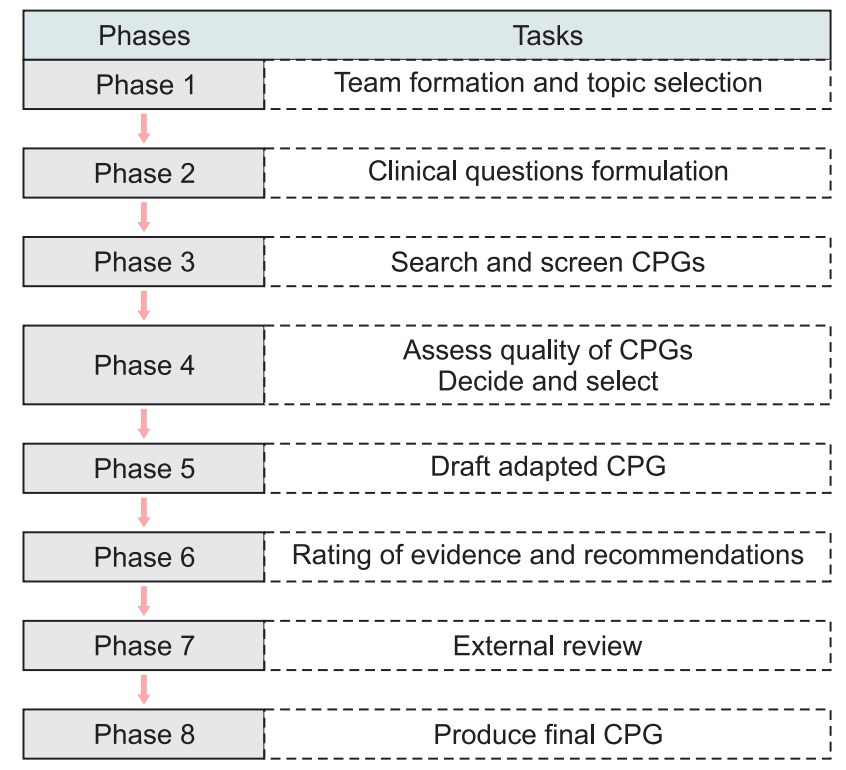

Fig. 1. Process for clinical practice guideline development. CPG: clinical practice guideline. 
Table 1. Level of Evidence

\begin{tabular}{cc}
\hline Level & Description \\
\hline A & $\begin{array}{c}\text { High-quality evidence from one or more high-quality, properly powered and conducted RCTs; systematic review or meta-analysis of these } \\
\text { studies }\end{array}$ \\
B & $\begin{array}{c}\text { Moderate-quality evidence from one or more moderate-quality RCTs, well-designed nonrandomized studies, observational studies, or } \\
\text { registry studies; systematic review or meta-analysis of these studies }\end{array}$ \\
C & Low-quality evidence from a case series or cohort/case-control studies of lesser quality \\
D & Consensus of expert opinion based on clinical experience \\
G & Evidence from high-quality clinical practice guidelines
\end{tabular}

RCT: randomized controlled trial.

Table 2. Grade of Recommendation

\begin{tabular}{|c|c|c|}
\hline Grade & Description & Phrases for writing recommendations \\
\hline I & $\begin{array}{l}\text { High-quality evidence (A) } \\
\text { Benefit }>>\text { Risk } \\
\text { High applicability of recommendations to routine clinical care practice }\end{array}$ & $\begin{array}{l}\text { Is recommended, is indicated, or is useful/effective/ } \\
\text { beneficial }\end{array}$ \\
\hline IIa & $\begin{array}{l}\text { Moderate-quality evidence (B) } \\
\text { Benefit }>\text { Risk } \\
\text { High or moderate applicability of recommendations to routine clinical care practice }\end{array}$ & $\begin{array}{l}\text { Should be recommended, can be useful/effective/ } \\
\text { beneficial }\end{array}$ \\
\hline $\mathrm{IIb}$ & $\begin{array}{l}\text { Low-quality evidence (C or D) } \\
\text { Benefit } \geq \text { Risk } \\
\text { High or moderate applicability of recommendations to routine clinical care practice }\end{array}$ & $\begin{array}{l}\text { May/might be recommended, may/might be } \\
\text { considered, may/might be reasonable }\end{array}$ \\
\hline III & $\begin{array}{l}\text { Low-quality evidence (C or D) } \\
\text { Benefit }<\text { Risk } \\
\text { Limited applicability of recommendations to routine clinical care practice }\end{array}$ & $\begin{array}{l}\text { Is not recommended, is not indicated, or may be } \\
\text { harmful }\end{array}$ \\
\hline
\end{tabular}

\section{Finalization of the clinical practice guideline}

The level of agreement of the Advisory Group on the draft guideline was examined. We conducted a questionnaire-based consensus-building survey twice using the Delphi technique. Questionnaires were sent out by email, and the recipients were requested to check the chosen box with " $\checkmark$ " or "o" indicating the degree of consensus to the recommendations, GOR, and LOE for each key question on a 9-point scale from 1 ("Strongly disagree") through 9 ("Strongly agree"). The first questionnaire was conducted with a 2 -week response deadline. The second questionnaire was formulated after the results of the first questionnaire were summarized, and then sent to the same recipients. In the second questionnaire, the same questionnaire items were used, but the response distribution of the first questionnaire for each item was also presented. The respondents who insisted on a response deviating from the normal distribution were requested to provide a detailed description of the reason. If more than half of all respondents agreed, consensus was considered to have been reached for that specific item.

After the opinions of the Advisory Group were collected and analyzed, the Development and Writing Groups modified, reevaluated, and finalized the recommendations.

The finalized guideline was reviewed internally by a panel of anesthesiologists who had not participated in guideline devel- opment, externally by related societies (Korean Society of Blood Transfusion, Korean Society for Patient Blood Management, Division of Human Blood Safety Surveillance in Korea Centers for Disease Control and Prevention) and through an opinion gathering process (over 2 weeks) via the webpage of the Korean Society of Anesthesiologists (http://www.anesthesia.or.kr/).

\section{Users of the guideline}

The target users of this guideline are anesthesiologists, other physicians in special and general hospitals, primary care physicians, military physicians, public health doctors, residents, and interns who perform blood transfusion during perioperative periods.

\section{Provision of further information about the guideline}

The full version and executive summary of the guideline can be retrieved from the website of the Korean Society of Anesthesiologists (http://www.anesthesia.or.kr/), where various transfusion-related materials are also provided. Furthermore, queries about the guideline can be posted here, which will be answered to the extent possible. 


\section{Revision schedule}

A partial or full revision of the guideline will be performed every 5 years based on the latest evidence. However, whenever new data or evidence emerge that rationally warrant revision of the guideline in relation to any aspect of RBC transfusion, it shall be revised accordingly.

\section{Sources of research funding and disclosure of conflicts of interest}

The development of this guideline was supported by the Korean Society of Anesthesiologists, which had no influence on its development. Each member of the Development and Writing Groups provided a disclosure of interest statement regarding the providers of pharmaceuticals, goods, and services related to the topics discussed in the guideline; no significant conflicts of interest were found to exist.

\section{Guidelines}

\section{Management of preoperative anemia}

- Recommendation: If moderate-to-severe bleeding is expected in an anemic patient scheduled for elective surgery, appropriate treatment should be recommended considering the cause and diagnosis of anemia to reduce unnecessary RBC transfusion (LOE: G, GOR: IIa); if moderate-to-severe bleeding is expected in an anemic patient scheduled for elective surgery, preoperative iron supplementation may be recommended to reduce $\mathrm{RBC}$ transfusion (LOE A, GOR: IIb); if moderate-to-severe bleeding is expected in an anemic patient scheduled for elective surgery, preoperative erythropoietin therapy may be recommended to reduce unnecessary RBC transfusion (LOE: A, GOR: IIb).

\section{Evidence summary}

In patients with anemia (hemoglobin level $<13.0 \mathrm{~g} / \mathrm{dl}$ for men and $<12.0 \mathrm{~g} / \mathrm{dl}$ for women), the cause of anemia should be evaluated and treated properly. If necessary, for anemia treatment, postponement of elective surgery should be considered [6]. Anemia screening tests (complete blood count, ferritin test, etc.) should be performed in patients scheduled for surgery or a procedure, and if anemia is present, it should be treated according to the cause to reduce unnecessary blood transfusion. Asymptomatic chronic anemia is treated with medication depending on the cause and diagnosis (e.g., oral or intravenous iron, vitamin B12, folic acid, and erythropoietin). In case of unexplained anemia without underlying iron deficiency, a specialist should be consulted depending on its severity. Anemia caused by vi- tamin B12 or folate deficiency, and confirmed by preoperative assessment, should be treated prior to surgery. ${ }^{1)}$ Patients at risk of bleeding should be assessed for anemia 4-8 weeks prior to elective surgery; if anemia is identified during the screening test, its cause should be examined [10]. Appropriate preoperative treatment of anemia can reduce the need for perioperative RBC transfusion. However, side effects and additional costs should considered in relation to medication for anemia. Appropriate preoperative anemia management and treatment should be performed prior to elective surgery in consultation with anesthesiologists and surgeons.

In patients with anemia caused by iron deficiency, unless there is a compelling need for immediate surgery, oral or intravenous iron supplementation may be considered $[11,12] .{ }^{1)}$ Randomized controlled trials examining the efficacy of preoperative oral iron supplementation have shown that the efficacy of iron supplementation therapy is unclear compared with placebo and active control in terms of hemoglobin level or perioperative allogeneic RBC transfusion [13,14]. However, in a questionnaire survey, members and consultants of the ASA strongly supported preoperative iron supplementation in patients with iron-deficiency anemia, if time allows it [5]. Whereas preoperative improvement of hemoglobin level may reduce the frequency and amount of RBC transfusion, appropriate consideration should be given to the side effects associated with iron supplementation, such as abdominal bloating, abdominal pain, constipation, and diarrhea, as well as the cost of iron supplementation therapy.

In patients with anemia without iron deficiency, erythropoietic therapy may be considered [10]. Studies in patients undergoing cardiac or orthopedic surgery revealed that perioperative transfusion was reduced in patients who had received erythropoietin preoperatively compared with the control group $[15,16]$. Although preoperative improvement of hemoglobin level may reduce the frequency and amount of RBC transfusion, appropriate consideration should be given to erythropoietin-induced side effects, such as shock, hypertension, seizures, palpitation, hypertensive encephalopathy/intracerebral hemorrhage, rash, and headache.

Treatment of preoperative anemia should be determined in consultation with the patient and surgeon in charge, considering expected intraoperative blood loss, the severity of anemia, cost of medication, health insurance coverage, and other relevant factors. Regarding the acceptance and applicability in Korea,

\footnotetext{
${ }^{1)}$ Guidelines on blood transfusion, 4th edition (complete revision in 2016). Ministry of Health and Welfare, Korea Centers for Disease Control and Prevention, Korean Society of Blood Transfusion.

Available from http://www.nih.go.kr/CDC/together/CdcKrTogether0302. jsp?menuIds=HOME001-MNU1154-MNU0004-MNU0088\&fid=51\&q type $=\&$ q_value $=\&$ cid $=70840$ \&pageNum $=1$
} 
some restrictions are expected concerning side effects, cost of medication, and insurance coverage.

\section{Appropriate storage time of packed red blood cells (pRBCs)}

- Recommendation: Use of pRBCs within the recommended storage time is endorsed for intraoperative or postoperative transfusion (LOE: A, G, GOR: I). Since there is no evidence for an increased risk of adverse events and 30-day mortality in patients following transfusion of pRBCs within the recommended storage time, transfusion of pRBCs within this time is recommended (LOE: A; GOR: I). Since there is no evidence of increased risk of nosocomial infections in patients that received transfusion of pRBCs within the recommended storage time, transfusion of pRBCs within this time is recommended (LOE: A, G; GOR: I).

\section{Evidence summary}

Non-RCTs on fresh versus older blood did not reveal any obvious differences in the effect of storage time on the in-hospital and 30-day post-hospitalization mortality, infectious complications, and intensive care unit or hospital stay [17-20]. In addition, there is no consensus among members of the ASA regarding blood transfusion without consideration of blood storage time [5].

AABB recommended the use of $\mathrm{pRBC}$ units within the recommended storage time rather than limiting the use to fresh units within 10 days after collection [7].

A meta-analysis of 13 RCTs in patients with acute severe disease or surgical bleeding, provided no evidence that fresh RBCs were better in terms of adult mortality (RR, 1.04; $95 \% \mathrm{Cl}$, 0.95-1.14). In three RCTs analyzing the correlation between RBC storage period and clinical outcome, the 30-day mortality was higher in the fresh RBC group by 4 per 1,000 patients ( $95 \%$ CI, five fewer deaths to 14 more deaths per 1000). Those trials yielded no evidence that administration of pRBCs within the recommended storage time increased the adverse events compared to fresh RBCs; however, the quality of evidence was low. Rather, fresh RBC transfusion was associated with a higher risk of nosocomial infections. In related studies, there were 43 nosocomial infections per 1000 patients (95\% CI, 1-86 more nosocomial infections per 1000 patients); however, the level of evidence was low [21-24].

Large-scale RCTs conducted in more than 5,000 patients in various clinical settings have yielded consistent results; there is no evidence that fresh $\mathrm{pRBC}$ transfusion reduces mortality. However, clinical trials conducted on the pRBC storage period to date have not considered patient factors, such as massive transfusion or exchange transfusion [7].

\section{Utilization of leukoreduction for RBC transfusion}

- Recommendation: To reduce the risk of febrile non-hemolytic transfusion reactions (FNHTRs), leukoreduction, especially as a prestorage treatment, is recommended (LOE: A, G; GOR:I). To reduce the risks of transfusion-transmitted cytomegalovirus infection (TT-CMV), human leukocyte antigen (HLA) alloimmunization, and other complications, leukoreduction in blood components is recommended (LOE: A, G; GOR: I). The use of leukoreduced RBCs is recommended for all patients with conditions requiring repeated blood transfusion, such as various types of leukemia, aplastic anemia, myelodysplastic syndrome, bone marrow failure, bone marrow transplant recipients, patients scheduled for allogeneic or autologous stem cell transplantation, immunocompromised patients with hematologic malignancy, congenital or acquired immune deficiency, leukemia, and undergoing chemotherapy, and recipients of allogeneic or autologous stem cell transplantation (LOE: A, G; GOR: I). Leukoreduction is recommended when administering RBC transfusion to patients undergoing cardiovascular surgery (LOE: A, G; GOR:I).

Evidence summary: Proinflammatory cytokines, such as IL-1, IL-8, and TNFa, are produced by leukocytes, accumulate in stored blood products, and cause febrile transfusion reactions during $\mathrm{RBC}$ transfusion [25,26]; thus, the use of leukoreduced/filtered RBCs has been recommended.

FNHTR occur in about $1 \%$ of all blood transfusions. An FNHTR is believed to have two etiologies: cytokines accumulated in pRBCs and the pyrogenic effects of IL-1 released by the patient's monocytes while host antibodies are reacting against donor leukocytes. FNHTRs can be efficiently addressed by reducing the leukocyte count by $90 \%-99 \%$. Highly efficient third-generation leukoreduction filters can reduce leukocytes by 9.9\%-99.99\% [27,28].

HLAs expressed on the surface of donor leukocytes induce HLA antigens in multi-transfused patients. Such alloimmunization increases the risk of graft rejection in patients awaiting transplantation and triggers platelet refraction in patients requiring repeated platelet transfusions, which make treatment very difficult. Leukoreduced transfusion can effectively prevent alloimmunization [29].

Monocytes are latently infected with cytomegalovirus (CMV). Both CMV and monocytes can be efficiently removed by leukoreduction. Leukoreduced transfusion can prevent CMV transmission as efficiently as CMV-negative transfusion [30].

Leukoreduced transfusion was shown to reduce ischemia-reperfusion injury in patients who had undergone cardiopulmonary bypass, and to reduce postoperative morbidity and mortality in patients with cardiovascular diseases [31,32].

For these reasons, the use of prestorage leukoreduced pRBCs, 
with leukoreduction performed immediately after collection, is a global trend, and universal leukoreduction is legally mandated in over 20 countries. This requires further consideration, given that leukoreduced/filtered pRBCs are reimbursed only for patients meeting criteria for insurance coverage in Korea, despite the recommendation of leukoreduction before RBC transfusion.

\section{Reversal of perioperative bleeding tendency}

\section{Warfarin reversal}

- Recommendation: In cases where rapid reversal of the anticoagulant effect of warfarin is necessary for patients scheduled for surgery, administration of fresh frozen plasma (FFP) or prothrombin complex concentrate (PCC) should be considered. Unless immediate warfarin reversal is required, the use of vitamin K should be considered (LOE: B; GOR: IIa).

Evidence summary: Reversing the effects of warfarin, a vitamin K-dependent anticoagulant, is based largely on three methods: administration of FFP, PCC, and vitamin K. If rapid warfarin reversal is required, FFP or PCC administration should be considered.

Since FFP is a blood product that contains blood-clotting factors, it has been used to reverse anticoagulation. However, administration of large amounts of FFP in the absence of clinical bleeding can result in circulatory overload, which carries the risk of various side effects, which typically arise from inadequate management and administration of blood products. Accordingly, the benefits of FFP are outweighed by the associated risks [5]. Therefore, FFP is not prioritized over alternative concentrates for warfarin reversal; however, since the use of other coagulation factors as safe alternatives to FFP is currently difficult in Korea, FFP administration should be considered for immediate warfarin reversal.

The use of PCC is on the rise, especially in Europe; it has been reported that normalization of prothrombin time (PT) can be achieved efficiently with a small amount of PCC. PCC has increasingly been employed worldwide, and its efficacy has been demonstrated in various ways.

Two types of PCC products exist: a three-factor PCC (factors II, IX, and X) and a four-factor PCC (factors II, VII, IX, and X). Observational studies and case reports have shown that PCC can significantly reduce PT levels. It can rapidly correct bleeding tendencies at much lower concentrations than FFP. Additionally, PCC is a non-blood product and thus works independently of blood type, and can avoid transfusion reactions such as infections, transfusion associated circulatory overload (TACO), transfusion-related acute lung injury (TRALI), and immunomodulation [33]. However, care should be taken to avoid hypercoagulation. According to reports, $0.003 \%$ of patients adminis- tered preoperatively with four-factor PCC develop thrombotic or ischemic complications [34,35]. PCC is now the treatment of choice in many guidelines worldwide; however, it has not yet been introduced in Korea.

The administration of vitamin $\mathrm{K}$ should be considered unless immediate reversal is required. When vitamin $\mathrm{K}$ is administered intravenously, reversal occurs in 4-6 hours, much faster than with oral vitamin K (24 hours) [36]; however, immediate effects cannot be expected in an emergency.

\section{Preoperative anticoagulant and antiplatelet} medications

- Recommendation: In patients scheduled for elective surgery, anticoagulant medication (e.g., warfarin, new oral anticoagulant $[\mathrm{NOAC}]$ ) can be discontinued considering the risks and benefits in consultation with a specialist. When necessary, the use of a short-acting anticoagulant replacement (e.g., heparin, low-molecular-weight heparin) is continued until immediately before the surgery. Except for a history of coronary-artery stent procedures associated with ischemic heart disease, temporary discontinuation of antiplatelet medication (e.g., thienopyridines such as clopidogrel, ticagrelor, or prasugrel) may be considered, allowing sufficient time for anticoagulation reversal, in consultation with a specialist. Continuous use of aspirin may be considered on a case-by-case basis (LOE: A, B; GOR: IIb).

Evidence summary: In patients with unexplained intraoperative bleeding who have been treated with anticoagulant or antiplatelet medications, a decision should be made on whether to continue or discontinue the medication. Two types of antithrombotic therapy exist: anticoagulation therapy to control the coagulation cascade, and antiplatelet therapy to reduce platelet activation (platelet adhesion, activation, and aggregation steps).

In a study comparing "low-molecular-weight heparin substituting for warfarin" and "warfarin cessation" groups, no significant intergroup differences were observed in the frequency of transfusion [37]. However, considering the risks of surgical bleeding and the benefits of avoiding stent thrombosis, it may be necessary to interrupt anticoagulation or continue bridge therapy with heparin or low molecular-weight heparin.

However, the efficacy of heparin substitution has not been clearly demonstrated in patients receiving antiplatelet medication due to ischemic heart disease. This is because stent thrombosis, which is a major factor in major adverse cardiac events, is caused by the action of platelets rather than coagulation factors in patients with ischemic heart disease. Coronary artery stenting has become increasingly widespread in recent years, with an increasing number of patients receiving dual antiplatelet therapy. Since anti-platelet agents developed to date irreversibly inhibit platelets, it has not been possible to use bridge therapy because 
efficacy is reversed in 5-7 days, which is the extinction period of platelets. Therefore, antiplatelet agents should be continued or discontinued 5-7 days prior to use, considering those risks and benefits.

In case of emergency surgery in a life-threatening condition with a high risk of bleeding, medication should be discontinued prior to surgery after informed consent is received, regardless of stenting status. If there is insufficient time to wait for the effects of medication to wear off, surgery should be performed immediately. Since two antiplatelet agents are routinely used for 12 months in patients with acute coronary syndrome regardless of stenting status, surgery is postponed or conducted under medication, except for emergency or cancer surgery. Today, bare metal stents are rarely used, and patients subjected to drug-eluting stent implantation, which is the mainstay of coronary stenting, may discontinue medication after 3 months depending on the surgical need and bleeding risk. However, in cases of increased risk of stent thrombosis associated with the number of stents implanted or increased vulnerability to high-severity thrombosis due to stents deployed at a proximal position, particular care should be taken on the decision to withdraw medication, regardless of its timing. Antiplatelet medication may be discontinued without consideration of the risks if the stents are not placed on major vessels, such as left anterior descending, left circumflex, and right coronary artery, but on smaller vessels such as obtuse marginal and diagonal branches, or are very distally placed such that stent thrombosis would not be life-threatening. In the case of surgery with a low risk of bleeding, the use of at least one antiplatelet agent is appropriate.

Observational studies demonstrated that intraoperative blood loss was significantly lower in patients who had discontinued clopidogrel therapy within 5 days of surgery compared with those who had discontinued clopidogrel therapy on the day of surgery; that there was no significant difference between 3- and 5 -day groups. Additionally, the use of clopidogrel significantly increased intraoperative blood loss and the amount of transfusion required $[38,39]$. Regarding aspirin, no significant differences were reported between groups of patients exposed and not exposed to aspirin in the amounts of perioperative blood loss and transfusion, and in the incidence of postoperative complications (myocardial infarction, severe bleeding, and death) [40]. However, the efficacy and impact of discontinuing aspirin therapy remain unclear. Continuous aspirin therapy is recommended in many clinical practice guidelines despite the high risk of bleeding; therefore, decisions on its cessation or continuation are permitted considering the risk of thrombosis and bleeding and the option of bridging therapy. Antiplatelet agents have not yet been developed for effective bridge therapy. Cangrelor, a reversible antiplatelet agent, has been developed and used as a bridge therapy for antiplatelet agents under FDA approval; however, it has not yet been introduced in Korea, and its efficacy and safety have not been confirmed. Intravenous glycoprotein IIb/IIIa inhibitors such as tirofiban are currently available in Korea, but care should be taken given the reported risk of bleeding events. Pending the development of stents using a new material that can reduce the duration of medication, and the development of safe and reversible antiplatelet agents ensuring safe treatment, careful decision-making among related specialists is required, weighing the risk of bleeding with the risk of thrombotic cardiovascular adverse events.

\section{Strategies for perioperative RBC transfusion: restrictive or liberal}

- Recommendation: In hemodynamically stable patients, a restrictive transfusion strategy, i.e., transfusing at a hemoglobin level lower than $7 \mathrm{~g} / \mathrm{dl}$, is recommended over a liberal transfusion strategy, i.e. transfusing at a hemoglobin level lower than 10 $\mathrm{g} / \mathrm{dl}$ (LOE: A, G; GOR: I). In patients undergoing major orthopedic or cardiac surgery, and in those with underlying cardiovascular disease, a restrictive transfusion strategy, i.e., transfusing at a hemoglobin level lower than $8 \mathrm{~g} / \mathrm{dl}$, is recommended (LOE: $A$, G; GOR: IIa).

Evidence summary: The 2015 ASA Practice Guidelines for Perioperative Blood Management include a subsection dedicated to restrictive versus liberal transfusion strategies [5], wherein baseline hemoglobin levels lower than $8 \mathrm{~g} / \mathrm{dl}$ (or hematocrit values less than $25 \%$ ) are typically considered to be restrictive. Citing a meta-analysis of RCTs, it states that a restrictive transfusion strategy reduces RBC transfusions compared with a liberal transfusion strategy without increasing mortality, the incidence of cardiac, neurological, or respiratory complications, and the length of hospital stay.

The 2016 guidelines of the AABB state that a hemoglobin level of 7-8 $\mathrm{g} / \mathrm{dl}$ is a restrictive RBC transfusion threshold and 9-10 $\mathrm{g} / \mathrm{dl}$ is a liberal RBC transfusion threshold [7]. These values are based on evidence from multiple large-scale RCTs conducted in various clinical settings involving more than 12,000 patients. The AABB recommends $7-8 \mathrm{~g} / \mathrm{dl}$ as the target hemoglobin level for RBC transfusion among hemodynamically stable inpatients. It also reports that, except in patients with acute myocardial infarction, there is no evidence that a restrictive transfusion strategy carries a higher risk than a liberal transfusion strategy, and that a restrictive transfusion strategy is associated with a decrease in the amount of blood products ordered, related costs, and incidence of rare but potentially serious transfusion reactions.

The AABB recommends two different hemoglobin levels for RBC transfusion in two patient groups, especially when 
adopting a restrictive transfusion strategy. For the first group, hemodynamically stable inpatients including those under intensive care, a hemoglobin level of $7 \mathrm{~g} / \mathrm{dl}$ is recommended as a restrictive RBC transfusion threshold. For the second group, patients undergoing orthopedic or cardiac surgery, and those with preexisting cardiovascular disease, a hemoglobin level of 8 $\mathrm{g} / \mathrm{dl}$ is recommended as a restrictive RBC transfusion threshold. Orthopedic and cardiac surgery patients were included as the second group because most RCTs have involved these two surgical procedures. The threshold value of $8 \mathrm{~g} / \mathrm{dl}$ recommended for the second patient group, compared with the first patient group including ICU patients, reflects the threshold value indicated by related RCTs, and was $8 \mathrm{~g} / \mathrm{dl}$ rather than $7 \mathrm{~g} / \mathrm{dl}$. Although the AABB Clinical Transfusion Medicine Committee suspected that patients in the second group might tolerate a threshold hemoglobin level of $7 \mathrm{~g} / \mathrm{dl}$ for a restrictive transfusion strategy, it recommended $8 \mathrm{~g} / \mathrm{dl}$ for this patient group. This was because a threshold level of $7 \mathrm{~g} / \mathrm{dl}$ had not been assessed in any RCT, and it was unclear if it could adversely affect functional recovery (in patients undergoing major orthopedic surgery) or myocardial infarction rates (in patients undergoing cardiac surgery or with chronic cardiovascular disease), even though it did not affect mortality.

Most RCTs on which the AABB recommendation for patients undergoing orthopedic surgery were based, included patients undergoing proximal femoral fracture surgery [41-43]. We therefore replaced "orthopedic surgery" as stated in the $A A B B$ recommendations with "major orthopedic surgery" The AABB guidelines recommended a hemoglobin level of $8 \mathrm{~g} / \mathrm{dl}$ as a restrictive $\mathrm{RBC}$ transfusion threshold for patients undergoing cardiac surgery. A recent large-scale multicenter clinical trial, including 5,243 patients undergoing cardiac surgery who were at moderate-to-high risk of postoperative mortality, reported that a restrictive transfusion strategy of transfusing at a hemoglobin level lower than $7.5 \mathrm{~g} / \mathrm{dl}$ after anesthesia, reduced the intra- and postoperative $\mathrm{RBC}$ transfusion requirements compared with a liberal transfusion strategy of transfusing at a hemoglobin level lower than $9.5 \mathrm{~g} / \mathrm{dl}$. Equivalent composite outcomes were reported, including all-cause mortality, myocardial infarction, stroke, and new-onset kidney failure requiring dialysis [44]. This trial was the largest of its kind, in terms of the number of patients undergoing cardiac surgery, to investigate the hemoglobin levels for RBC transfusion. If the results of such large-scale RCTs are reflected in future guideline updates, more clearly defined recommendations will be issued regarding hemoglobin levels for a restrictive transfusion strategy in patients undergoing cardiac surgery.

Notably, the AABB recommended no hemoglobin levels for a restrictive or liberal transfusion strategy in patients with acute coronary syndrome among those with underlying cardiovascu- lar disease. This subgroup was not included because the AABB Committee found that the sample size of 154 was not large enough to provide reliable evidence, although a liberal transfusion strategy was associated with lower mortality in two small trials $[45,46]$. By not presenting recommendations based on clinical settings with insufficient evidential backup, the AABB Committee have allowed for flexible decision-making by clinicians in the setting of threshold values for transfusion initiation.

However, a meta-analysis conducted in 2016 reported that a restrictive transfusion strategy (hemoglobin level $<8.0 \mathrm{~g} / \mathrm{dl}$ ) for patients with acute and chronic cardiovascular diseases increased the risk of acute coronary syndrome. In addition, it was noted that it is desirable to retain a liberal transfusion strategy (hemoglobin level $\geq 8.0 \mathrm{~g} / \mathrm{dl}$ ) until evidence is presented to the contrary from large-scale RCTs [47]. In the fourth edition of the 2016 transfusion guideline published in Korea, ${ }^{1)}$ different hemoglobin levels are recommended for patients with cardiovascular diseases depending on the condition of individual patients: $<8.0$ $\mathrm{g} / \mathrm{dl}$ in stable and asymptomatic patients, $8-10 \mathrm{~g} / \mathrm{dl}$ in patients with acute coronary syndrome (e.g., acute myocardial infarction) or unstable angina, and $10 \mathrm{~g} / \mathrm{dl}$ in patients with evolving or symptomatic myocardial ischemia.

Therefore, pending the results of an ongoing large-scale RCT (ClinicalTrials.gov Identifier: NCT02981407), a liberal transfusion strategy appears desirable in patients with acute coronary syndrome.

\section{Perioperative blood management protocols}

\section{Multimodal protocols}

- Recommendation: The use of multimodal protocols and algorithms should be considered as strategies to reduce perioperative blood product utilization (LOE: A, G; GOR: IIa).

Evidence summary: The 2015 ASA Practice Guidelines for Perioperative Blood Management recommended that multimodal protocols or algorithms may be employed as a strategy to reduce perioperative blood product utilization [5]. However, the ASA has not yet recommended any single protocol or algorithm. Intervention components of a multimodal protocol include transfusion-related expert consultation, the use of transfusion algorithms, point-of-care testing, and perioperative blood-saving measures. Multimodal protocols or algorithms are used to

\footnotetext{
${ }^{1)}$ Guidelines on blood transfusion, 4th edition (complete revision in 2016). Ministry of Health and Welfare, Korea Centers for Disease Control and Prevention, Korean Society of Blood Transfusion.

Available from http://www.nih.go.kr/CDC/together/CdcKrTogether0302. jsp?menuIds=HOME001-MNU1154-MNU0004-MNU0088\&fid=51\&q type $=\&$ q_value $=\& \mathrm{cid}=70840 \&$ pageNum $=1$
} 
determine whether transfusion is necessary or when selecting intervention pathways customized to individual clinical settings [5].

RCTs comparing transfusion management that applies multimodal protocols or algorithms based on coagulation tests or hemoglobin levels, with routine transfusion management have yielded varying results [48-50]. Whereas transfusions after cardiac surgery based on an on-site coagulation monitoring algorithm revealed no significant differences in the hemostatic effect [48], the implementation of a transfusion algorithm based on a coagulation test during cardiac surgery reduced the levels of FFP and platelet transfusion [49]. The implementation of a comprehensive blood conservation algorithm was reported to reduce the frequency of allogeneic transfusion during hip surgery [50]. Transfusion management based on a thromboelastography (TEG)-guided algorithm in cardiac surgery has been reported to reduce transfusion requirements compared with conventional transfusion management based on clinical decision and routine coagulation tests $[51,52]$. According to an RCT, transfusion management of burn patients using a rotational thromboelastometry (ROTEM)-guided algorithm reduced the blood transfusion requirements compared with transfusion management without use of the algorithm [53]. These studies reported on transfusion protocols or algorithms that involve various intervention components, but did not present the effects of any individual intervention component on outcome. The implementation of multimodal protocols or algorithms has the advantage of reducing the frequency and amount of blood transfusion; however, the increased number of tests at different stages of an algorithm may increase healthcare expenditure.

\section{Massive transfusion protocols}

- Recommendation: Implementation of a massive transfusion protocol may be considered in a patient with massive bleeding as a strategy to optimize the delivery of blood products ( $L O E: C$, G, GOR: $I I b)$.

Evidence summary: Guidelines on the implementation of massive transfusion protocols in patients with massive bleeding requiring such a transfusion recommend that these protocols may be used as a strategy to optimize the delivery of blood products $[5,6]$. Massive transfusion protocols can be implemented to minimize the adverse effects of hypovolemia and dilutional coagulopathy in case of life-threatening massive surgical or traumatic bleeding requiring large amounts of available blood resources [5]. A massive transfusion protocol should include recognition, communication, rapid delivery of blood products, and the involvement of appropriate surgery and intervention radiology.

Massive bleeding can be defined as blood loss of $\geq 5 \mathrm{~L}$ in the first 24 hours (around $70 \mathrm{ml} / \mathrm{kg}$ or $5 \mathrm{~L}$ in a $70 \mathrm{~kg}$ adult), or $\geq$ $50 \%$ of the total blood volume in the first 3 hours, or $\geq 150 \mathrm{ml} /$ min. Clinically, it can be defined as systolic blood pressure $\leq 90$ $\mathrm{mmHg}$ and/or a heart rate $\geq 110$ beats/min [6]. Massive transfusion is defined as transfusing 8-10 units in less than 24 hours or 4-5 units in less than 1 hour. The standard pRBC:FFP:platelet ratio suggested by massive transfusion protocols for patients with life-threatening hemorrhage is $1: 1: 1$ [5], whereby each of these blood products is issued in a pack of 4-6 units. Types of blood available for emergency transfusion of patients with unknown blood type are group $\mathrm{O}$ for $\mathrm{pRBCs}$ and group $\mathrm{AB}$ for FFP and platelets. Group $\mathrm{O} \mathrm{RhD}$ - negative $\mathrm{pRBC}$ is recommended, but $\mathrm{RhD}$-positive $\mathrm{pRBC}$ may be used if $\mathrm{RhD}$-negative pRBC is not available. An observational study reported that onsite implementation of a massive transfusion protocol resulted in a higher FFP:pRBC transfusion ratio and a decrease in the use of crystalloid, with a normal body temperature and raised hemoglobin level [54].

Mass transfusion protocols can be used as life-saving transfusion protocols in patients with life-threatening massive hemorrhage. However, utilization of large amounts of blood products for one patient raises concerns about the allocation of limited blood products, and delays in delivery to other patients in need of transfusion due to the continued preparation for massive transfusion.

\section{Maximal surgical blood-order schedule}

- Recommendation: A maximal surgical blood-order schedule adjusted to each institution's policy may be considered as a strategy to improve the efficiency of blood-ordering practices, (LOE: B, G; GOR: IIb).

Evidence summary: The 2015 ASA Practice Guidelines for Perioperative Blood Management recommended that a maximum surgical blood-order schedule may be used as a strategy to improve the efficiency of blood-ordering practices [5].

Observational studies reported that preparing blood products according to a maximal surgical blood-order schedule or surgical blood-order equation reduces unnecessary transfusions and prescription errors, thus improving operating room efficiency, patient safety, and reducing healthcare costs [55-57]. An RCT reported that the surgical blood-order equation was more efficient than the maximum surgical blood-order schedule at reducing the crossmatch-to-transfusion ratio in total hip arthroplasty [58].

A maximal surgical blood-order schedule should be specifically implemented based on the statistics of the electronic medical records of the individual institution, and updated on a regular basis through the periodic analysis of order volume and utilization of blood products. Implementation of a maximal sur- 
gical blood-order system has the advantages of avoiding unnecessary cross-match testing, reducing the waste of issued units, and allocating blood products with limited availability more efficiently to non-surgical patients. However, it does not provide allowances for emergency transfusions in the case of blood loss that exceeds the anticipated amount. This should be addressed by establishing an institutional framework that ensures the availability of a stock of blood products that can be delivered immediately in emergencies.

\section{Strategies to reduce $\mathrm{RBC}$ transfusions}

\section{Preadmission donation of autologous blood and acute normovolemic hemodilution}

- Recommendation: As a strategy to reduce pRBC transfusion, preadmission donation of autologous blood may be considered, if there is sufficient time for RBC regeneration prior to surgery (LOE: A, G; GOR: $I I b)$. As a strategy to reduce pRBC transfusion, acute normovolemic hemodilution may be considered in patients at high risk for massive bleeding (e.g., cardiac, thoracic, major orthopedic, and hepatic surgery) (LOE: A, G; GOR: $I I b)$.

Evidence summary: RCTs have reported that preadmission donation of autologous blood reduces transfusion rates and the volume of blood transfused [59,60]. The 2015 ASA Practice Guidelines for Perioperative Blood Management stated that a patient preferring autologous blood should be given the opportunity for preadmission donation of autologous blood only if there is sufficient time for $\mathrm{RBC}$ regeneration prior to surgery [5]. The transfusion of autologous blood does not prevent clerical errors and side effects, such as transfusion-related bacterial infections. Furthermore, the acceptability of this procedure is considered low in Korea, due to patient discomfort associated with repeated in-hospital treatments, the burden of increased medical costs, and the limited choice of surgical appointments.

Related RCTs have reported that acute normovolemic hemodilution is effective at reducing the transfusion rates and blood volume transfused in patients undergoing cardiac, orthopedic, thoracic, and hepatic surgery [61-63]. A recent meta-analysis of RCTs examining the efficacy of acute normovolemic hemodilution in cardiac surgery also concluded that this strategy reduced transfusion rates, the volume of blood transfused, and blood loss [64]. However, other meta-analyses have raised concerns about the true efficacy and safety of the procedure $[65,66]$. In addition, the degree of hemodilution varies between studies, and the safe range of hemodilution remaining unclear. Despite the proven efficacy of acute normovolemic hemodilution at reducing the volume of blood transfused and the transfusion rate in surgery during which massive bleeding is expected [62,63,67], its benefits in the case of mild bleeding have yet to be verified. Additionally, there could be problems with blood storage and management. Moreover, the use of this strategy is limited in patients with hypovolemia, anemia, or ischemic disease. The physiological effects of acute normovolemic hemodilution are not clearly understood; it is difficult to examine the physiological effects of this strategy in a clinical trial because the topic touches on issues of patient safety and ethics. To address this, a study exploring an experimental research model is underway [68]. Acute normovolemic hemodilution has great potential for acceptability because patients feel reasonably comfortable with it; however, it is only applicable when sufficient time and human and material resources are available for blood collection.

\section{Use of antifibrinolytic}

- Recommendation: As a strategy to reduce pRBC transfusion in patients undergoing cardiopulmonary bypass, the use of antifibrinolytics is recommended (I). The use of antifibrinolytics should be considered for the prevention of excessive bleeding associated with major orthopedic surgery, liver surgery, and other invasive procedures (IIa) (LOE: A, G; GOR: I/IIa).

\section{Evidence summary}

Tranexamic acid (TXA): TXA is a synthetic derivative of the amino acid lysine, which competitively inhibits plasminogen activation, thus preventing impaired fibrinolysis. TXA is distributed throughout all body tissues and has a plasma half-life of $120 \mathrm{~min}$. It is used in surgical procedures for its ability to reduce blood loss and the need for transfusion.

Meta-analyses of RCTs indicate that preoperative or intraoperative administration of TXA to prevent excessive bleeding significantly reduces perioperative blood loss, the number of patients receiving transfusion, and the volume of blood projects transfused [69-71]. Other randomized trials comparing TXA with placebo or control reported no intergroup differences in reoperation and mortality due to stroke or myocardial infarction, renal insufficiency, and hemorrhage [72,73].

Meta-analyses of RCTs have reported that TXA administration before tourniquet release to prevent excessive bleeding after total knee arthroplasty and total hip arthroplasty could reduce bleeding compared with a placebo group [70,71]. In contrast, one RCT reported that postoperative TXA administration to patients undergoing cardiac surgery had no effect until 12 hours after the procedure [74].

Seizures have been reported with high doses of TXA, but evidence of other adverse effects is limited [75]. However, given that few studies have been conducted in TXA-treated patients at high risk of thromboembolism, and few guidelines or protocols refer to such cases, we present a list of contraindications, relying on expert opinions, as follows. Absolute contraindications 
include a history of thromboembolic disease, disseminated intravascular coagulation or consumptive coagulopathy, renal insufficiency, coronary artery or intravascular stenting in the preceding 6-12 months, and acute subarachnoid hemorrhage; Relative contraindications may include uncontrollable seizures, renal insufficiency, high risk of intravascular embolism, history of coagulopathy, and oral anticoagulant medication.

Among various possible doses, a single dose of $1 \mathrm{~g}$ is recommended, and additional infusion of $500 \mathrm{mg} / \mathrm{h}$ may be considered [76].

$\mathcal{\varepsilon}$-aminocaproic acid: $\varepsilon$-aminocaproic acid (EACA) is a synthetic amino acid that inhibits plasminogen activator and plasmin and thus indirectly inhibits fibrinolysis. Its potency is about 10-fold lower than that of TXA. A loading dose of $150 \mathrm{mg} / \mathrm{kg}$ is administered, followed by a continuous infusion of $15 \mathrm{mg} / \mathrm{kg} / \mathrm{h}$. Its initial elimination half-life is $60-75 \mathrm{~min}$, and the agent should be infused continuously to maintain its therapeutic effect until the risk of bleeding diminishes. EACA may be a potential alternative to TXA when the latter is unavailable. If the use of TXA is difficult, EACA may be a potential alternative. Meta-analyses of RCTs have reported that preoperative or intraoperative EACA administration is effective at reducing perioperative blood loss, the number of patients receiving transfusions in major cardiac, orthopedic, and hepatic surgery, and the volume of blood transfused $[69,71,77]$. An RCT comparing EACA with placebo found that administrating EACA prior to tourniquet release to prevent excessive bleeding after total knee arthroplasty reduced blood loss and the need for RBC transfusion [71].

Aprotinin: Aprotinin is a serine protease inhibitor that inhibits fibrinolysis by inactivating free plasmin. This antifibrinolytic agent was withdrawn from the market in 2007 for safety reasons due to its adverse effect on renal function and the high incidence of anaphylactic reactions. Currently, its use is approved only for myocardial revascularization, such as coronary artery bypass surgery [78].

\section{Use of intraoperative blood salvage}

- Recommendation: As a strategy to reduce pRBC transfusion, intraoperative blood salvage is recommended for the indicated conditions (LOE: A, G; GOR: I). Intraoperative blood salvage should be considered to reduce intraoperative $\mathrm{pRBC}$ transfusion in the following cases: (1) blood loss of $\geq 1,000 \mathrm{ml}$ or $\geq 20 \%$ of the expected blood loss; (2) low hemoglobin levels and high risk of bleeding; (3) rare blood group or multiple unexpected antibodies; and (4) the patient's refusal to receive allogenic blood transfusion ( $L O E: A, B, G$; GOR: IIa). The use of leukoreduction filters may be considered when reinfusing the recovered RBCs (IIb). In particular, to reduce the risk of amniotic fluid embolism in obstetric surgery, and the risk of metastasis in cancer surgery, the use of microfine filters (e.g., Log 5 cell filter) should be considered (IIa) (LOE: A, B, G; GOR: IIb/IIa).

Evidence summary: Intraoperative blood salvage, also called autotransfusion, is an important blood conservation strategy that efficiently reduces the volume of blood transfused during surgery. Many RCTs, meta-analyses, and transfusion guidelines have demonstrated its efficacy in a variety of surgical interventions, including cardiac, vascular, orthopedic, and obstetric surgery [5,6,79-82]. Different guidelines are focused on slightly different indications; however, all recommend it in cases where reduction of $\mathrm{RBC}$ transfusion is required, for example, anticipated massive bleeding, ongoing uncontrolled bleeding, or difficulty in preparing pRBCs for any reasons [6].

The use of leukoreduction filters is recommended when reinfusing recovered blood [5,6]. In particular, many studies have demonstrated that risks of systemic metastasis in cancer surgery and amniotic fluid embolism in obstetric surgery can be avoided by using leukoreduction filters [6,83-87]. Recent retrospective studies found no intergroup differences in cancer recurrence and survival rate between autotransfusion and non-transfusion groups among patients undergoing radical prostatectomy or radical cystectomy $[83,84]$. In addition, one prospective study reported that autotransfusion during hepatocellular carcinoma surgery had no effect on recurrence rates [85]. However, to ensure safe blood salvage during cancer surgery, it is recommended to use leukoreduction filters and to exclude the area near the tumor site from blood suction [6]. There are theoretical concerns that blood salvage during obstetric surgery may increase the risk of amniotic fluid embolism; however, this has not yet been reported in association with intraoperative blood salvage, and recent studies have reported that leukoreduction filters efficiently reduce the risk of contamination through amniotic fluid and fetal RBCs $[86,87]$.

In general, intraoperative blood salvage is not recommended in the presence of bowel contamination caused by stagnant gastrointestinal content. Although several studies, including RCTs, have reported that intraoperative blood salvage does not increase the incidence of wound infections, and is not associated with pathogens that cause postoperative pneumonia and urinary tract infections in patients undergoing laparotomy for abdominal trauma $[88,89]$, many manufacturers state bowel contamination as a contraindication for intraoperative blood salvage. More research needs to be conducted to address this.

\section{Perioperative patient monitoring}

\section{Monitoring for surgical site bleeding}

- Recommendation: To ensure adequate care depending on the cause of bleeding, e.g., bleeding due to trauma or microvascular bleeding due to coagulopathy, it is recommended to 
periodically conduct a visual assessment of the surgical site jointly with the surgeon (LOE: G; GOR: I). For quantitative measurement of intraoperative blood loss, it is recommended to use standard methods, including checking suction canisters, surgical sponges, and surgical drains (LOE: G; GOR: I).

Evidence summary: The 2015 ASA Practice Guidelines suggested the need for periodic visual assessment of surgical site bleeding in patients undergoing surgery. It recommended careful periodic visual assessment of the surgical field jointly with the surgeon to determine the extent and cause of bleeding, and the use of standard methods for the quantitative measurement of blood loss, including the examination of suction canisters, surgical sponges, and surgical drains [5]. Although limited literature on perioperative visual surveillance of surgical site bleeding and methods of measuring quantitative blood loss is available, there was strong consensus among clinical practice guideline committee and advisory committee members on the need for such monitoring.

It is important to periodically check surgical site bleeding jointly with the surgeon to confirm whether the bleeding is due to injury (trauma or incision) or coagulopathy, and to provide appropriate care accordingly. Quantitative assessment of intraoperative blood loss is also important to determine the extent of circulatory blood loss in the patient. Visual assessment of the extent and cause of bleeding is subject to the judgment of the anesthesiologist and the surgeon, and over- or under-estimation of lost blood can occur due to fluids other than blood (i.e., ascites or peritoneal lavage fluids). In conclusion, careful periodic intraoperative visual assessment is necessary to ensure the extent and cause of bleeding is accurately diagnosed, and to obtain onsite measures to reduce bleeding.

\section{Monitoring the perfusion of vital organs}

- Recommendation: In case of intraoperative transfusion, it is recommended to monitor the perfusion of vital organs using standard parameters (blood pressure, heart rate, oxygen saturation, electrocardiography, and body temperature) in addition to observing the patient's clinical symptoms and physical examination features (LOE: G; GOR: I). Additional monitoring, including echocardiography, urine output, cerebral function (noninvasive cerebral oximetry and near-infrared spectroscopy), arterial blood gasses, and mixed venous oxygen saturation may be considered (LOE: G; GOR: IIb).

Evidence summary: The 2015 ASA Practice Guidelines suggested the need to adequately monitor the perfusion of vital organs after intraoperative RBC transfusion. It recommended the use of standard monitors and checking the patient's clinical symptoms and physical examination features, with additional monitoring of echocardiography, urine output, cerebral function, arterial blood gasses, and mixed venous oxygen saturation [5]. Literature focused on the monitoring of vital organ perfusion after RBC transfusion and transfusion-related clinical outcomes is limited; however, there was strong consensus among the clinical practice guideline committee and advisory committee members on the need for such monitoring.

After RBC transfusion, the perfusion status of vital organs should be assessed using perfusion monitors, and adequate treatment should be provided to ensure appropriate transfusion. However, the post-transfusion perfusion status of vital organs does not guarantee improved tissue oxygenation of vital organs [90]. The costs associated with additional examinations should also be considered. To conclude, in addition to checking the patient's clinical symptoms and physical examination features after RBC transfusion, it is necessary to assess the perfusion status of vital organs using standard parameters (blood pressure, heart rate, oxygen saturation, electrocardiography, and body temperature). Performing additional examinations is expected to enhance diagnostic accuracy regarding the perfusion status of vital organs.

\section{Monitoring for anemia}

- Recommendation: In hemodynamically stable patients, if anemia is suspected due to bleeding or based on clinical signs and other objective indicators (e.g., blood pressure, heart rate, arterial oxygen saturation, electrocardiography, urine output, and cerebral oxygen saturation), measurement of hemoglobin or hematocrit is recommended ( $L O E: C, D, G$; GOR: I). In hemodynamically stable patients without acute bleeding, hemoglobin or hematocrit measurement may be considered before and after each unit of RBC transfused. Since over- or underestimation of hemoglobin or hematocrit levels can occur due to hemoconcentration (in the case of acute bleeding) or hemodilution (in the case of fluid infusion), respectively, care should be taken when interpreting the measured values, and measurements at shorter intervals may be considered ( $L O E: C, D, G$; GOR: $I I b$ ). Although laboratory measurement of hemoglobin or hematocrit remains the gold standard, measurement via near-patient or point-ofcare testing may be considered in cases such as those involving acute bleeding where test results should be obtained rapidly to provide the necessary care (LOE: C, D; GOR: IIb).

Evidence summary: Although the efficacy of monitoring for perioperative anemia has not been sufficiently researched, if anemia is suspected due to bleeding or based on clinical signs and other objective indicators (e.g., blood pressure, heart rate, arterial oxygen saturation, electrocardiography, urine output, and cerebral oxygen saturation), measurement of hemoglobin or hematocrit is recommended based on estimated blood loss or 
clinical signs. This can provide important information necessary for the accurate diagnosis of the patient's condition and for the decision on whether to transfuse RBCs $[5,6]{ }^{1)}$

In case of hemodynamic stability and the absence of acute bleeding, there may be a need to measure a patient's hemoglobin or hematocrit before and after each unit to confirm their condition and decide whether additional RBC transfusion is necessary. Hemoglobin levels reach equilibrium about 15 minutes after completing transfusion in the absence of ongoing active bleeding; thus, hemoglobin levels can be measured as early as 15 minutes after RBC transfusion [91,92]. Since hemoglobin level is determined by both RBCs mass and plasma volume, the measured hemoglobin level may be falsely higher than the actual level due to hemoconcentration despite considerable blood loss in the case of acute bleeding, or lower than the actual level in the case of hemodilution due to intravenous fluid administration to address hypovolemia. Thus, in case of active ongoing bleeding, it should be considered that hemoglobin levels will not accurately reflect the degree of reduced red cell mass until a stable euvolemic state has been achieved. To improve diagnostic accuracy, determination of hemoglobin or hematocrit levels at shorter intervals should be considered in patients with acute bleeding or hypovolemia. However, since hemoglobin or hematocrit is measured through an invasive blood test, the testing frequency should be determined carefully, considering the patient's discomfort and the blood volume removed for testing [93,94].

In the case of acute bleeding, measurement of hemoglobin or hematocrit via near-patient or point-of-care tests may be helpful to rapidly obtain test results and provide the necessary care. However, hemoglobin or hematocrit measured in standard laboratory tests remains the current gold standard.

\section{Transfusion-related adverse reactions}

- Recommendation: Since adverse reactions to blood transfusion during and after blood transfusion, such as acute hemolytic transfusion reactions, transfusion-related acute lung injury, transfusion-associated circulatory overload, bacterial contamination, allergic reactions, and citrate toxicity, have been reported, albeit rarely, it is recommended that all patients undergoing blood transfusion are monitored for such adverse reactions (LOE: $C, D, G$; GOR: I). Before transfusion, the volume, color, and condition of the blood product bag should be visually inspected, and the patient's baseline condition and vital signs should be

\footnotetext{
${ }^{1)}$ Guidelines on blood transfusion, 4th edition (complete revision in 2016). Ministry of Health and Welfare, Korea Centers for Disease Control and Prevention, Korean Society of Blood Transfusion. Available from http://www.nih.go.kr/CDC/together/CdcKrTogether0302. jsp?menuIds=HOME001-MNU1154-MNU0004-MNU0088\&fid=51\&q type $=\&$ q_value $=\&$ cid $=70840 \&$ pageNum $=1$
}

monitored. Given that severe transfusion reactions, such as anaphylactic reactions, hemolytic transfusion reactions, and septic shock, often occur within the first 15 minutes of initiating blood transfusion, it is recommended to observe the patient's condition for 5-15 minutes and to record all vital signs. This is followed by periodic monitoring of the patient's condition throughout the blood transfusion and checking the patient's condition and vital signs upon completion of transfusion (LOE: C, D, G; GOR: I). Considering the current lack of monitoring tools and methods for accurate diagnosis of transfusion reactions, periodic intraand postoperative monitoring for signs of adverse reactions to transfusion, such as hyperthermia, hemoglobinuria, microvascular bleeding, hypoxemia, respiratory distress, increased airway pressure, urticaria, hypotension, and hypocalcemia, are recommended ( $L O E: C, D, G$; GOR: I). If there are signs of suspected transfusion reactions (tachycardia, rash, respiratory distress, hypotension, fever, etc.) during or after transfusion, it is recommended that transfusion be stopped immediately, and appropriate diagnostic tests performed (I). Treatment options include administration of antihistamines or steroids. Administration of intramuscular or intravenous adrenaline may be considered in life-threatening situations (IIb) (LOE: C, D, G/C, D; GOR: I/IIb).

Evidence summary: Signs of intra- or postoperative adverse reactions related to $\mathrm{RBC}$ transfusion include the following: signs of acute hemolytic transfusion reactions such as hyperthermia, hemoglobinuria, and microvascular bleeding; signs of TRALI syndrome or TACO including hypoxemia, respiratory distress, and increased peak airway pressure; signs of bacterial contamination such as hyperthermia and hypotension; signs of allergic reactions such as urticaria; and signs of citrate toxicity such as hypocalcemia (Fig. 2) [5,6,95-97]. ${ }^{1)}$ Furthermore, several non-randomized comparative studies have reported that RBC transfusion may be associated with a higher risk of infection [98-101]. Therefore, it is recommended that all patients receiving transfusion are monitored for the occurrence of these transfusion-related adverse reactions.

Although evidence on specific monitoring tools or methods for diagnosing transfusion adverse reactions, and the timing and intervals of such monitoring is currently lacking, all selected guidelines recommend checking the patient's blood condition before transfusion, and monitoring for signs of adverse reactions periodically during and after transfusion [5,6]. ${ }^{1)}$ Before transfusion, the volume, color, and condition of the bag of blood product delivered from the blood bank should be checked by visual inspection. The blood product tagged with a crossmatch label (there may be no crossmatch label in the case of emergency transfusion) should be checked against the patient's name, admission number, and $\mathrm{ABO}-\mathrm{RhD}$ group to ensure that all records are identical. The use of proven computer-based devices, such 


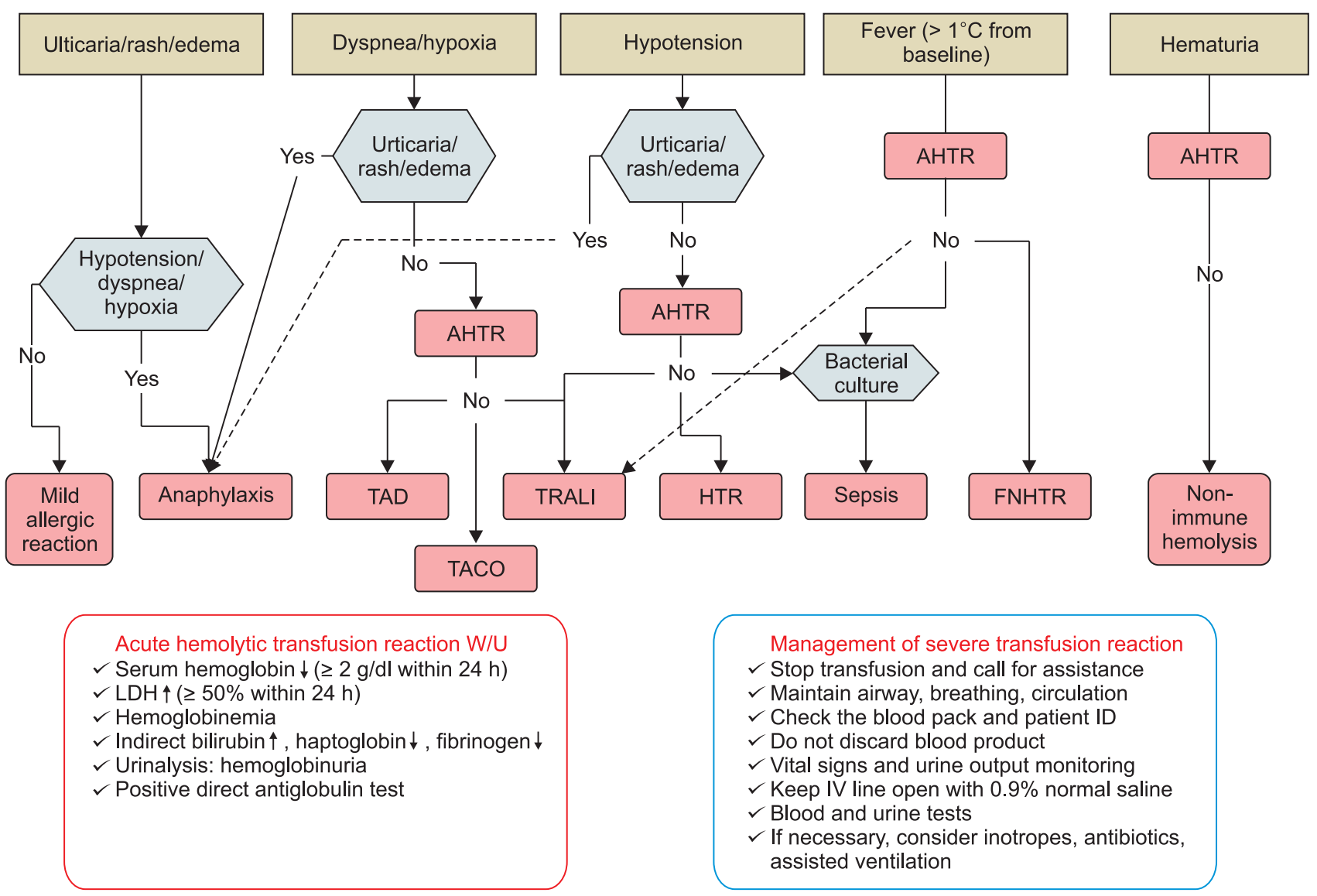

Fig. 2. Transfusion reaction algorithm. AHTR: acute hemolytic transfusion reaction, TAD: transfusion-associated dyspnea, TACO: transfusionassociated circulatory overload, TRALI: transfusion-related acute lung injury, HTR: hypotensive transfusion reaction, FNHTR: febrile non-hemolytic transfusion reaction, $\mathrm{LDH}$ : lactate dehydrogenase.

as a personal digital assistant, can be useful for patient identification during blood transfusion because they can reduce administrative errors. ${ }^{1)}$ Based on the transfusion protocol of each institution, periodic assessment of vital signs (i.e., pulse rate, blood pressure, body temperature, and respiratory rate) and any signs of an adverse transfusion reactions (i.e., hyperthermia, hemoglobinuria, microvascular bleeding, hypoxemia, respiratory distress, increased airway pressure, urticaria, hypotension, and hypocalcemia) during and after transfusion is recommended. Given that severe transfusion reactions, such as anaphylactic reactions, hemolytic transfusion reactions, and septic shock, often occur within the first 15 minutes of blood transfusion, ${ }^{2)}$ it is recommended to observe the patient's condition for 5-15 minutes after beginning the transfusion and to record all vital signs. This should be followed by periodically monitoring the patient's condition throughout the blood transfusion and checking the patient's condition and vital signs after completing the transfusion $[5,6]^{1)}$

If there are signs of a transfusion reaction (tachycardia, rash, respiratory distress, hypotension, fever, etc.), it is recommended to stop the transfusion immediately and perform appropriate diagnostic tests $[5,6] .{ }^{1)}$ Replacement of intravenous administration sets (i.e., blood bag, tubing, burettes, and extension tubing) and maintaining an intravenous line with $0.9 \%$ normal saline for emergency management may be helpful. It should also be considered that abnormal vital signs may have other causes. Treatment options include the administration of antihistamine or steroids. Administration of intramuscular or intravenous adrenaline may be considered in life-threatening situations [6]. To prevent transfusion reactions, antipyretic analgesics or antihistamines may be administered before initiating the transfusion

\footnotetext{
${ }^{1)}$ Guidelines on blood transfusion, 4th edition (complete revision in 2016). Ministry of Health and Welfare, Korea Centers for Disease Control and Prevention, Korean Society of Blood Transfusion.

Available from http://www.nih.go.kr/CDC/together/CdcKrTogether0302. jsp?menuIds=HOME001-MNU1154-MNU0004-MNU0088\&fid=51\&q type $=\&$ q_value $=\&$ cid $=70840 \&$ pageNum $=1$

${ }^{2)}$ Han GS, Park GU, Song EY. Transfusion Medicine. Seoul, Korea Medical Book Publishing Company. 2014, p 79.
} 
(30 minutes for oral administration and 10 minutes for intravenous administration). However, this method is controversial and is generally not recommended due to a lack of clinical evidence. In particular, there may be side effects of the drugs, which do not cause early signs of transfusion reactions, such as fever and urticaria, and can make early diagnosis of serious transfusion reactions difficult [102].

If an acute transfusion reaction is suspected, the medical staff and blood bank should be notified thereof, and the transfusion reaction report should be attached to the medical record. Concurrently, the patient should be immediately treated as per protocol of each institution. Further examinations and analyses should be performed after reporting the incident to the blood bank, hospital president (for medical institutions without their own blood bank), or the blood transfusion management committee. The occurrence of specific transfusion adverse effects (AIDS, hepatitis B, hepatitis C, and other infectious diseases) should be reported to the Minister of Health and Welfare by the head of the medical institution, as prescribed by the Ordinance of the Ministry of Health and Welfare. ${ }^{1,3)}$

\section{Monitoring for coagulopathy}

- Recommendation: If coagulopathy is suspected during or after surgery, standard coagulation tests (PT/INR, aPTT, platelet count, and fibrinogen concentration) should be considered. Additionally, a viscoelastic assay should be considered if the necessary tools are available (LOE: A; GOR: IIa). If platelet dysfunction is suspected during or after surgery, point-of-care platelet function tests may be considered, given the limitation of viscoelastic assays in detecting platelet dysfunction caused by antiplatelet agents (LOE: B; GOR: IIb).

Evidence summary: Available standard coagulation tests include prothrombin time and international normalized ratio (PT/ INR), activated partial thromboplastin time (aPTT), platelet count, and fibrinogen concentration. PT/INR and aPTT, which constitute a coagulation screen, are time-consuming traditional

\footnotetext{
${ }^{1)}$ Guidelines on blood transfusion, 4th edition (complete revision in 2016). Ministry of Health and Welfare, Korea Centers for Disease Control and Prevention, Korean Society of Blood Transfusion.

Available from http://www.nih.go.kr/CDC/together/CdcKrTogether0302. jsp?menuIds=HOME001-MNU1154-MNU0004-MNU0088\&fid=51\&q type $=\&$ q_value $=\&$ cid $=70840 \&$ pageNum $=1$

${ }^{3)}$ Article 10, Blood Management Act (measures against specific side effects of blood transfusion); Article 3, Enforcement Regulation of the Blood Management Act (specific side effects of blood transfusion); Article 13, Enforcement Regulation of the Blood Management Act (reporting of specific side effects of blood transfusion, etc.). Available from http://www. law.go.kr/LSW//lsSc.do?tabMenuId=tab18\&p1=\&subMenu=1\&nwYn=1 \&section $=\&$ tabNo $=\&$ query $=\% \mathrm{ED} \% 98 \% 88 \% \mathrm{EC} \% 95 \% \mathrm{~A} 1 \% \mathrm{EA} \% \mathrm{~B} 4 \% 80 \%$ EB\%A6\%AC\%EB\%B2\%95\#undefined
}

lab coagulation tests and are thus unsuitable for the dynamic clinical situation of ongoing perioperative bleeding. Fibrinogen concentration and platelet count are gaining importance as methods of monitoring coagulopathy, and traditional coagulation screens alone (including PT/INR and aPTT) are not sufficient to reflect the overall condition of blood clotting [103].

Contrary to these methods, a viscoelastic assay may be used as a time-saving point-of-care test, to comprehensively and effectively reflect the clotting condition. Currently, two clinically available point-of-care diagnostic tools are available for the viscoelastic assay: thromboelastometry (ROTEM, TEM International, Germany) and thromboelastography (TEG, Haemonetics Corp., USA). A viscoelastic assay requires less time than conventional lab coagulation tests and has proven efficacy for estimating the necessity of massive blood transfusion in surgical and trauma patients, the incidence of thrombosis and thromboembolism, and mortality [104,105]. Moreover, viscoelastic assays enable targeted treatment by rapidly monitoring blood coagulation and fibrinolysis, and help to reduce blood product requirements through targeted blood component therapy [52].

Despite the widespread use of viscoelastic assays, their superiority to standard coagulation tests in terms of patient prognosis has not been reported in the literature, and their clinical feasibility has been questioned by some researchers. In a retrospective study of patients that underwent cardiovascular surgery, the use of viscoelastic assays was associated with reduced blood product transfusion and thromboembolism; however, there was no effect on mortality [106]. A systematic review conducted by Da Luz et al. [107] concluded that viscoelastic assays are useful for predicting blood transfusion requirements when diagnosing early traumatic coagulopathy, but they have no effect on mortality and other important clinical outcomes. In a more recent systematic review, Hunt et al. [108] stated that viscoelastic assays cannot be recommended, given the lack of evidence supporting the accuracy of thromboelastography and thromboelastometry.

There is ongoing debate regarding results obtained with viscoelastic assays and standard coagulation tests. Studies have found that results obtained with these two approaches are consistent to some extent [109], whereas others have reported discrepancies even between thromboelastography and thromboelastometry [110]. Considering variation in the coagulation process among individual patients and the large deviations in the results among individual institutions, there is a need for disambiguation and standardization of viscoelastic assays. As a complementary strategy, two blood samples may be taken, one of which can be used for viscoelastic assays and the other for standard coagulation tests.

Another limitation of viscoelastic assays is that they are not suitable for detecting and monitoring platelet dysfunction caused by antiplatelet agents. If platelet dysfunction is suspected, 
point-of-care platelet function tests (e.g., whole-blood impedancemetry, multiple electrode platelet aggregometry [Multiplate]) may be considered, in addition to standard coagulation tests and viscoelastic assays, to predict the risk of platelet dysfunction [111].

\section{Conclusion}

The present work, the Korean Clinical Practice Guideline for Perioperative Red Blood Cell Transfusion, was developed as a clinical practice guideline tailored to the Korean perioperative setting in consultation with external experts. In developing the guidelines, we adopted the clinical practice guideline development method "adaptation of guidelines" and extracted key questions and recommendations from various related sources regarding the issues surrounding perioperative $\mathrm{RBC}$ transfusion, i.e., preoperative anemia management, optimal storage period and use of leukoreduction filters for RBC transfusion, reversal of perioperative bleeding tendency, perioperative $\mathrm{RBC}$ transfusion strategies, appropriate blood management protocols, strategies for reducing transfusion requirements, and patient monitoring throughout perioperative transfusion. The present work is limited to perioperative RBC transfusion; however, experience gained through the development of standard clinical practice guidelines is expected to be applied to the development of guidelines in other areas of clinical practice. This guideline will be updated periodically, and additional recommendations will be developed and added. We plan to distribute this work through various channels, such as conferences and publicity activities, so that it can support doctors with decision-making when performing perioperative $\mathrm{RBC}$ transfusion at a practical level.

\section{Acknowledgments}

Supported by the Korean Society of Anesthesiologists and developed under the direction of Tae-Yop Kim, M.D., Director, Committee on Academic Affairs.

\section{Funding Statement}

This work was supported by the Korean Society of Anesthesiologists.

\section{Conflicts of Interest}

No potential conflict of interest relevant to this article was reported.

\section{Author Contributions}

Bon-Nyeo Koo (Conceptualization; Investigation; Project administration; Writing - original draft; Writing - review \& editing)

Min A Kwon (Conceptualization; Investigation; Project administration; Writing - original draft; Writing - review \& editing)

Sang-Hyun Kim (Conceptualization; Investigation; Methodology; Project administration; Writing - original draft; Writing review \& editing)

Jong Yeop Kim (Conceptualization; Investigation; Project administration; Writing - original draft; Writing - review \& editing)

Young-Jin Moon (Conceptualization; Investigation; Methodology; Project administration; Writing - original draft; Writing review \& editing)

Sun Young Park (Conceptualization; Investigation; Project administration; Writing - original draft; Writing - review \& editing)

Eun-Ho Lee (Conceptualization; Investigation; Methodology; Project administration; Resources; Supervision; Writing - original draft; Writing - review \& editing)

Min Suk Chae (Conceptualization; Investigation; Project administration; Writing - original draft; Writing - review \& editing) Sung Uk Choi (Conceptualization; Investigation; Project administration; Writing - original draft; Writing - review \& editing) Jeong-Hyun Choi (Conceptualization; Investigation; Project administration; Writing - original draft; Writing - review \& editing)

Jin-Young Hwang (Conceptualization; Investigation; Project administration; Writing - original draft; Writing - review \& editing)

\section{ORCID}

Bon-Nyeo Koo, https://orcid.org/0000-0002-3189-1673

Min A Kwon, https://orcid.org/0000-0002-7253-3768

Sang-Hyun Kim, https://orcid.org/0000-0001-6267-7365

Jong Yeop Kim, https://orcid.org/0000-0003-3402-365X

Young-Jin Moon, https://orcid.org/0000-0003-3719-1691

Sun Young Park, https://orcid.org/0000-0003-2588-3324

Eun-Ho Lee, https://orcid.org/0000-0002-6369-7429

Min Suk Chae, https://orcid.org/0000-0002-1426-4651

Sung Uk Choi, https://orcid.org/0000-0003-3609-2253

Jeong-Hyun Choi, https://orcid.org/0000-0003-1995-1220

Jin-Young Hwang, https://orcid.org/0000-0003-1719-4350 


\section{References}

1. Consensus conference. Perioperative red blood cell transfusion. JAMA 1988; 260: 2700-3.

2. Cho N, Kim J, Lee WS. Survey on the usage of leukocyte reduced and irradiated blood components in Korea (2007-2013). Korean J Blood Transfus 2015; 26: 159-73.

3. Wang JK, Klein HG. Red blood cell transfusion in the treatment and management of anaemia: the search for the elusive transfusion trigger. Vox Sang 2010; 98: 2-11.

4. The ADAPTE Collaboration. ADAPTE Resource Toolkit for Guideline Adaptation Version 2.0. 2010 [Internet]. Pitlochry: The Guidelines International Network [updated 2010 Mar; cited 2018 Nov 19]. Available from https://www.g-i-n.net/document-store/working-groupsdocuments/adaptation/adapte-resource-toolkit-guideline-adaptation-2-0.pdf/view.

5. American Society of Anesthesiologists Task Force on Perioperative Blood Management. Practice guidelines for perioperative blood management: an updated report by the American Society of Anesthesiologists Task Force on Perioperative Blood Management*. Anesthesiology 2015; 122: 241-75.

6. Klein AA, Arnold P, Bingham RM, Brohi K, Clark R, Collis R, et al. AAGBI guidelines: the use of blood components and their alternatives 2016. Anaesthesia 2016; 71: 829-42.

7. Carson JL, Guyatt G, Heddle NM, Grossman BJ, Cohn CS, Fung MK, et al. Clinical Practice Guidelines From the AABB: Red Blood Cell Transfusion Thresholds and Storage. JAMA 2016; 316: 2025-35.

8. AGREE Next Steps Consortium. The AGREE II Instrument: Electronic version [Internet]. AGREE; 2009 May[updated 2017 Dec; cited 2018 Nov 19]. Available from https://www.agreetrust.org/wp-content/uploads/2017/12/AGREE-II-Users-Manual-and-23-item-Instrument-2009Update-2017.pdf.

9. Oh MK, Jo H, Lee YK. Improving the reliability of clinical practice guideline appraisals: effects of the Korean AGREE II scoring guide. J Korean Med Sci 2014; 29: 771-5.

10. Kozek-Langenecker SA, Afshari A, Albaladejo P, Santullano CA, De Robertis E, Filipescu DC, et al. Management of severe perioperative bleeding: guidelines from the European Society of Anaesthesiology. Eur J Anaesthesiol 2013; 30: 270-382.

11. Cuenca J, García-Erce JA, Martínez F, Cardona R, Pérez-Serrano L, Muñoz M. Preoperative haematinics and transfusion protocol reduce the need for transfusion after total knee replacement. Int J Surg 2007; 5: 89-94.

12. Lidder PG, Sanders G, Whitehead E, Douie WJ, Mellor N, Lewis SJ, et al. Pre-operative oral iron supplementation reduces blood transfusion in colorectal surgery - a prospective, randomised, controlled trial. Ann R Coll Surg Engl 2007; 89: 418-21.

13. Andrews CM, Lane DW, Bradley JG. Iron pre-load for major joint replacement. Transfus Med 1997; 7: 281-6.

14. Garrido-Martín P, Nassar-Mansur MI, de la Llana-Ducrós R, Virgos-Aller TM, Rodríguez Fortunez PM, Ávalos-Pinto R, et al. The effect of intravenous and oral iron administration on perioperative anaemia and transfusion requirements in patients undergoing elective cardiac surgery: a randomized clinical trial. Interact Cardiovasc Thorac Surg 2012; 15: 1013-8.

15. Weber EW, Slappendel R, Hémon Y, Mähler S, Dalén T, Rouwet E, et al. Effects of epoetin alfa on blood transfusions and postoperative recovery in orthopaedic surgery: the European Epoetin Alfa Surgery Trial (EEST). Eur J Anaesthesiol 2005; 22: 249-57.

16. Yoo YC, Shim JK, Kim JC, Jo YY, Lee JH, Kwak YL. Effect of single recombinant human erythropoietin injection on transfusion requirements in preoperatively anemic patients undergoing valvular heart surgery. Anesthesiology 2011; 115: 929-37.

17. Koch CG, Li L, Sessler DI, Figueroa P, Hoeltge GA, Mihaljevic T, et al. Duration of red-cell storage and complications after cardiac surgery. N Engl J Med 2008; 358: 1229-39.

18. Cata JP, Klein EA, Hoeltge GA, Dalton JE, Mascha E, O'Hara J, et al. Blood storage duration and biochemical recurrence of cancer after radical prostatectomy. Mayo Clin Proc 2011; 86: 120-7.

19. McKenny M, Ryan T, Tate H, Graham B, Young VK, Dowd N. Age of transfused blood is not associated with increased postoperative adverse outcome after cardiac surgery. Br J Anaesth 2011; 106: 643-9.

20. Chen J, Singhapricha T, Memarzadeh M, Ziman A, Yuan S, Hu KQ, et al. Storage age of transfused red blood cells during liver transplantation and its intraoperative and postoperative effects. World J Surg 2012; 36: 2436-42.

21. Dhabangi A, Ainomugisha B, Cserti-Gazdewich C, Ddungu H, Kyeyune D, Musisi E, et al. Effect of transfusion of red blood cells with longer vs shorter storage duration on elevated blood lactate levels in children with severe anemia: the TOTAL randomized clinical trial. JAMA 2015; 314: 2514-23.

22. Lacroix J, Hébert PC, Fergusson DA, Tinmouth A, Cook DJ, Marshall JC, et al. Age of transfused blood in critically ill adults. N Engl J Med 2015; 372: 1410-8.

23. Steiner ME, Ness PM, Assmann SF, Triulzi DJ, Sloan SR, Delaney M, et al. Effects of red-cell storage duration on patients undergoing cardiac surgery. N Engl J Med 2015; 372: 1419-29.

24. Alexander PE, Barty R, Fei Y, Vandvik PO, Pai M, Siemieniuk RA, et al. Transfusion of fresher vs older red blood cells in hospitalized patients: a systematic review and meta-analysis. Blood 2016; 127: 400-10.

25. Heddle NM, Klama LN, Griffith L, Roberts R, Shukla G, Kelton JG. A prospective study to identify the risk factors associated with acute reactions to platelet and red cell transfusions. Transfusion 1993; 33: 794-7.

26. Stack G, Snyder EL. Cytokine generation in stored platelet concentrates. Transfusion 1994; 34: 20-5. 
27. Cardigan R, Sutherland J, Garwood M, Krailadsiri P, Seghatchian J, Beard M, et al. The effect of leucocyte depletion on the quality of freshfrozen plasma. Br J Haematol 2001; 114: 233-40.

28. Yomtovian R, Gernsheimer T, Assmann SF, Mohandas K, Lee TH, Kalish LA, et al. WBC reduction in RBC concentrates by prestorage filtration: multicenter experience. Transfusion 2001; 41: 1030-6.

29. Seftel MD, Growe GH, Petraszko T, Benny WB, Le A, Lee CY, et al. Universal prestorage leukoreduction in Canada decreases platelet alloimmunization and refractoriness. Blood 2004; 103: 333-9.

30. Hall S, Danby R, Osman H, Peniket A, Rocha V, Craddock C, et al. Transfusion in CMV seronegative T-depleted allogeneic stem cell transplant recipients with CMV-unselected blood components results in zero CMV transmissions in the era of universal leukocyte reduction: a U.K. dual centre experience. Transfus Med 2015; 25: 418-23.

31. van de Watering LM, Hermans J, Houbiers JG, van den Broek PJ, Bouter H, Boer F, et al. Beneficial effects of leukocyte depletion of transfused blood on postoperative complications in patients undergoing cardiac surgery: a randomized clinical trial. Circulation 1998; 97: $562-8$.

32. Bilgin YM, van de Watering LM, Eijsman L, Versteegh MI, Brand R, van Oers MH, et al. Double-blind, randomized controlled trial on the effect of leukocyte-depleted erythrocyte transfusions in cardiac valve surgery. Circulation 2004; 109: 2755-60.

33. Rossaint R, Bouillon B, Cerny V, Coats TJ, Duranteau J, Fernández-Mondéjar E, et al. The European guideline on management of major bleeding and coagulopathy following trauma: fourth edition. Crit Care 2016; 20: 100.

34. Schick KS, Fertmann JM, Jauch KW, Hoffmann JN. Prothrombin complex concentrate in surgical patients: retrospective evaluation of vitamin K antagonist reversal and treatment of severe bleeding. Crit Care 2009; 13: R191.

35. Hanke AA, Joch C, Görlinger K. Long-term safety and efficacy of a pasteurized nanofiltrated prothrombin complex concentrate (Beriplex $\mathrm{P} / \mathrm{N})$ : a pharmacovigilance study. Br J Anaesth 2013; 110: 764-72.

36. Watson HG, Baglin T, Laidlaw SL, Makris M, Preston FE. A comparison of the efficacy and rate of response to oral and intravenous Vitamin $\mathrm{K}$ in reversal of over-anticoagulation with warfarin. Br J Haematol 2001; 115: 145-9.

37. Dotan ZA, Mor Y, Leibovitch I, Varon D, Golomb J, Duvdevani M, et al. The efficacy and safety of perioperative low molecular weight heparin substitution in patients on chronic oral anticoagulant therapy undergoing transurethral prostatectomy for bladder outlet obstruction. J Urol 2002; 168: 610-3.

38. Shim JK, Choi YS, Oh YJ, Bang SO, Yoo KJ, Kwak YL.. Effects of preoperative aspirin and clopidogrel therapy on perioperative blood loss and blood transfusion requirements in patients undergoing off-pump coronary artery bypass graft surgery. J Thorac Cardiovasc Surg 2007; 134: 59-64.

39. Firanescu CE, Martens EJ, Schönberger JP, Soliman Hamad MA, van Straten AH. Postoperative blood loss in patients undergoing coronary artery bypass surgery after preoperative treatment with clopidogrel. A prospective randomised controlled study. Eur J Cardiothorac Surg 2009; 36: 856-62.

40. Devereaux PJ, Mrkobrada M, Sessler DI, Leslie K, Alonso-Coello P, Kurz A, et al. Aspirin in patients undergoing noncardiac surgery. N Engl J Med 2014; 370: 1494-503.

41. Foss NB, Kristensen MT, Jensen PS, Palm H, Krasheninnikoff M, Kehlet H. The effects of liberal versus restrictive transfusion thresholds on ambulation after hip fracture surgery. Transfusion 2009; 49: 227-34.

42. Carson JL, Terrin ML, Noveck H, Sanders DW, Chaitman BR, Rhoads GG, et al. Liberal or restrictive transfusion in high-risk patients after hip surgery. N Engl J Med 2011; 365: 2453-62.

43. Gregersen M, Borris LC, Damsgaard EM. Postoperative blood transfusion strategy in frail, anemic elderly patients with hip fracture: the TRIFE randomized controlled trial. Acta Orthop 2015; 86: 363-72.

44. Mazer CD, Whitlock RP, Fergusson DA, Hall J, Belley-Cote E, Connolly K, et al. Restrictive or liberal red-cell transfusion for cardiac surgery. N Engl J Med 2017; 377: 2133-44.

45. Cooper HA, Rao SV, Greenberg MD, Rumsey MP, McKenzie M, Alcorn KW, et al. Conservative versus liberal red cell transfusion in acute myocardial infarction (the CRIT Randomized Pilot Study). Am J Cardiol 2011; 108: 1108-11.

46. Carson JL, Brooks MM, Abbott JD, Chaitman B, Kelsey SF, Triulzi DJ, et al. Liberal versus restrictive transfusion thresholds for patients with symptomatic coronary artery disease. Am Heart J 2013; 165: 964-71.

47. Docherty AB, O'Donnell R, Brunskill S, Trivella M, Doree C, Holst L, et al. Effect of restrictive versus liberal transfusion strategies on outcomes in patients with cardiovascular disease in a non-cardiac surgery setting: systematic review and meta-analysis. BMJ 2016; 352: i1351.

48. Capraro L, Kuitunen A, Salmenperä M, Kekomäki R. On-site coagulation monitoring does not affect hemostatic outcome after cardiac surgery. Acta Anaesthesiol Scand 2001; 45: 200-6.

49. Nuttall GA, Oliver WC, Santrach PJ, Bryant S, Dearani JA, Schaff HV, et al. Efficacy of a simple intraoperative transfusion algorithm for nonerythrocyte component utilization after cardiopulmonary bypass. Anesthesiology 2001; 94: 773-81.

50. Wong CJ, Vandervoort MK, Vandervoort SL, Donner A, Zou G, MacDonald JK, et al. A cluster-randomized controlled trial of a blood conservation algorithm in patients undergoing total hip joint arthroplasty. Transfusion 2007; 47: 832-41.

51. Shore-Lesserson L, Manspeizer HE, DePerio M, Francis S, Vela-Cantos F, Ergin MA. Thromboelastography-guided transfusion algorithm reduces transfusions in complex cardiac surgery. Anesth Analg 1999; 88: 312-9. 
52. Ak K, Isbir CS, Tetik S, Atalan N, Tekeli A, Aljodi M, et al. Thromboelastography-based transfusion algorithm reduces blood product use after elective CABG: a prospective randomized study. J Card Surg 2009; 24: 404-10.

53. Schaden E, Kimberger O, Kraincuk P, Baron DM, Metnitz PG, Kozek-Langenecker S. Perioperative treatment algorithm for bleeding burn patients reduces allogeneic blood product requirements. Br J Anaesth 2012; 109: 376-81.

54. Simmons JW, White CE, Eastridge BJ, Mace JE, Wade CE, Blackbourne LH. Impact of policy change on US Army combat transfusion practices. J Trauma 2010; 69 Suppl 1: S75-80.

55. Kajja I, Bimenya GS, Eindhoven GB, ten Duis HJ, Sibinga CT. Surgical blood order equation in femoral fracture surgery. Transfus Med 2011; 21: 7-12.

56. Dexter F, Ledolter J, Davis E, Witkowski TA, Herman JH, Epstein RH. Systematic criteria for type and screen based on procedure's probability of erythrocyte transfusion. Anesthesiology 2012; 116: 768-78.

57. Frank SM, Rothschild JA, Masear CG, Rivers RJ, Merritt WT, Savage WJ, et al. Optimizing preoperative blood ordering with data acquired from an anesthesia information management system. Anesthesiology 2013; 118: 1286-97.

58. Nuttall GA, Santrach PJ, Oliver WC Jr, Ereth MH, Horlocker TT, Cabanela ME, et al. A prospective randomized trial of the surgical blood order equation for ordering red cells for total hip arthroplasty patients. Transfusion 1998; 38: 828-33.

59. Kajikawa M, Nonami T, Kurokawa T, Hashimoto S, Harada A, Nakao A, et al. Autologous blood transfusion for hepatectomy in patients with cirrhosis and hepatocellular carcinoma: use of recombinant human erythropoietin. Surgery 1994; 115: 727-34.

60. Bouchard D, Marcheix B, Al-Shamary S, Vanden Eynden F, Demers P, Robitaille D, et al. Preoperative autologous blood donation reduces the need for allogeneic blood products: a prospective randomized study. Can J Surg 2008; 51: 422-7.

61. Matot I, Scheinin O, Jurim O, Eid A. Effectiveness of acute normovolemic hemodilution to minimize allogeneic blood transfusion in major liver resections. Anesthesiology 2002; 97: 794-800.

62. Bennett J, Haynes S, Torella F, Grainger H, McCollum C. Acute normovolemic hemodilution in moderate blood loss surgery: a randomized controlled trial. Transfusion 2006; 46: 1097-103.

63. Jarnagin WR, Gonen M, Maithel SK, Fong Y, D'Angelica MI, Dematteo RP, et al. A prospective randomized trial of acute normovolemic hemodilution compared to standard intraoperative management in patients undergoing major hepatic resection. Ann Surg 2008; 248: 3609.

64. Barile L, Fominskiy E, Di Tomasso N, Alpìzar Castro LE, Landoni G, De Luca M, et al. Acute normovolemic hemodilution reduces allogeneic red blood cell transfusion in cardiac surgery: a systematic review and meta-analysis of randomized trials. Anesth Analg 2017; 124: 743-52.

65. Segal JB, Blasco-Colmenares E, Norris EJ, Guallar E. Preoperative acute normovolemic hemodilution: a meta-analysis. Transfusion 2004; 44: 632-44.

66. Zhou X, Zhang C, Wang Y, Yu L, Yan M. Preoperative acute normovolemic hemodilution for minimizing allogeneic blood transfusion: a meta-analysis. Anesth Analg 2015; 121: 1443-55.

67. Naqash IA, Draboo MA, Lone AQ, Nengroo SH, Kirmani A, Bhat AR. Evaluation of acute normovolemic hemodilution and autotransfusion in neurosurgical patients undergoing excision of intracranial meningioma. J Anaesthesiol Clin Pharmacol 2011; 27: 54-8.

68. Sims CR 3rd, Delima LR, Calimaran A, Hester R, Pruett WA. Validating the physiologic model hummod as a substitute for clinical trials involving acute normovolemic hemodilution. Anesth Analg 2018; 126: 93-101.

69. Menichetti A, Tritapepe L, Ruvolo G, Speziale G, Cogliati A, Di Giovanni C, et al. Changes in coagulation patterns, blood loss and blood use after cardiopulmonary bypass: aprotinin vs tranexamic acid vs epsilon aminocaproic acid. J Cardiovasc Surg (Torino) 1996; 37 : 401-7.

70. Ekbäck G, Axelsson K, Ryttberg L, Edlund B, Kjellberg J, Weckström J, et al. Tranexamic acid reduces blood loss in total hip replacement surgery. Anesth Analg 2000; 91: 1124-30.

71. Camarasa MA, Ollé G, Serra-Prat M, Martín A, Sánchez M, Ricós P, et al. Efficacy of aminocaproic, tranexamic acids in the control of bleeding during total knee replacement: a randomized clinical trial. Br J Anaesth 2006; 96: 576-82.

72. Karski JM, Teasdale SJ, Norman P, Carroll J, VanKessel K, Wong P, et al. Prevention of bleeding after cardiopulmonary bypass with highdose tranexamic acid. Double-blind, randomized clinical trial. J Thorac Cardiovasc Surg 1995; 110: 835-42.

73. Andreasen JJ, Nielsen C. Prophylactic tranexamic acid in elective, primary coronary artery bypass surgery using cardiopulmonary bypass. Eur J Cardiothorac Surg 2004; 26: 311-7.

74. Casati V, Bellotti F, Gerli C, Franco A, Oppizzi M, Cossolini M, et al. Tranexamic acid administration after cardiac surgery: a prospective, randomized, double-blind, placebo-controlled study. Anesthesiology 2001; 94: 8-14.

75. Sharma V, Katznelson R, Jerath A, Garrido-Olivares L, Carroll J, Rao V, et al. The association between tranexamic acid and convulsive seizures after cardiac surgery: a multivariate analysis in 11529 patients. Anaesthesia 2014; 69: 124-30.

76. Hunt BJ. The current place of tranexamic acid in the management of bleeding. Anaesthesia 2015; 70 Suppl 1: 50-3.

77. Dalmau A, Sabaté A, Acosta F, Garcia-Huete L, Koo M, Sansano T, et al. Tranexamic acid reduces red cell transfusion better than epsilonaminocaproic acid or placebo in liver transplantation. Anesth Analg 2000; 91: 29-34.

78. Ortmann E, Besser MW, Klein AA. Antifibrinolytic agents in current anaesthetic practice. Br J Anaesth 2013; 111: 549-63.

79. Ekbäck G, Schött U, Axelsson K, Carlberg M. Perioperative autotransfusion and functional coagulation analysis in total hip replacement. Acta Anaesthesiol Scand 1995; 39: 390-5. 
80. Rainaldi MP, Tazzari PL, Scagliarini G, Borghi B, Conte R. Blood salvage during caesarean section. Br J Anaesth 1998; 80: 195-8.

81. Mercer KG, Spark JI, Berridge DC, Kent PJ, Scott DJ. Randomized clinical trial of intraoperative autotransfusion in surgery for abdominal aortic aneurysm. Br J Surg 2004; 91: 1443-8.

82. Niranjan G, Asimakopoulos G, Karagounis A, Cockerill G, Thompson M, Chandrasekaran V. Effects of cell saver autologous blood transfusion on blood loss and homologous blood transfusion requirements in patients undergoing cardiac surgery on- versus offcardiopulmonary bypass: a randomised trial. Eur J Cardiothorac Surg 2006; 30: 271-7.

83. Nieder AM, Carmack AJ, Sved PD, Kim SS, Manoharan M, Soloway MS. Intraoperative cell salvage during radical prostatectomy is not associated with greater biochemical recurrence rate. Urology 2005; 65: 730-4.

84. Nieder AM, Manoharan M, Yang Y, Soloway MS. Intraoperative cell salvage during radical cystectomy does not affect long-term survival. Urology 2007; 69: 881-4.

85. Muscari F, Suc B, Vigouroux D, Duffas JP, Migueres I, Mathieu A, et al. Blood salvage autotransfusion during transplantation for hepatocarcinoma: does it increase the risk of neoplastic recurrence? Transpl Int 2005; 18: 1236-9.

86. Waters JH, Biscotti C, Potter PS, Phillipson E. Amniotic fluid removal during cell salvage in the cesarean section patient. Anesthesiology 2000; 92: 1531-6.

87. Sullivan I, Faulds J, Ralph C. Contamination of salvaged maternal blood by amniotic fluid and fetal red cells during elective Caesarean section. Br J Anaesth 2008; 101: 225-9.

88. Ozmen V, McSwain NE Jr, Nichols RL, Smith J, Flint LM. Autotransfusion of potentially culture-positive blood (CPB) in abdominal trauma: preliminary data from a prospective study. J Trauma 1992; 32: 36-9.

89. Bowley DM, Barker P, Boffard KD. Intraoperative blood salvage in penetrating abdominal trauma: a randomised, controlled trial. World J Surg 2006; 30: 1074-80.

90. Sair M, Etherington PJ, Peter Winlove C, Evans TW. Tissue oxygenation and perfusion in patients with systemic sepsis. Crit Care Med 2001; 29: 1343-9.

91. Wiesen AR, Hospenthal DR, Byrd JC, Glass KL, Howard RS, Diehl LF. Equilibration of hemoglobin concentration after transfusion in medical inpatients not actively bleeding. Ann Intern Med 1994; 121: 278-30.

92. Elizalde JI, Clemente J, Marín JL, Panés J, Aragón B, Mas A, et al. Early changes in hemoglobin and hematocrit levels after packed red cell transfusion in patients with acute anemia. Transfusion 1997; 37: 573-6.

93. Salisbury AC, Reid KJ, Alexander KP, Masoudi FA, Lai SM, Chan PS, et al. Diagnostic blood loss from phlebotomy and hospital-acquired anemia during acute myocardial infarction. Arch Intern Med 2011; 171: 1646-53.

94. Stefanini M. Iatrogenic anemia (can it be prevented?). J Thromb Haemost 2014; 12: 1591

95. Bux J, Becker F, Seeger W, Kilpatrick D, Chapman J, Waters A. Transfusion-related acute lung injury due to HLA-A2-specific antibodies in recipient and NB1-specific antibodies in donor blood. Br J Haematol 1996; 93: 707-13.

96. Yasuda H, Ohto H, Yamaguchi O, Sakuma S, Suzuki T, Mita M, et al. Three episodes of delayed hemolytic transfusion reactions due to multiple red cell antibodies, anti-Di, anti-Jk and anti-E. Transfus Sci 2000; 23: 107-12.

97. Chung YT, Wu YC, Chen YH. Postoperative pulmonary edema, transfusion-related?--a case report. Acta Anaesthesiol Sin 2003; 41: 43-6.

98. Chelemer SB, Prato BS, Cox PM Jr, O'Connor GT, Morton JR. Association of bacterial infection and red blood cell transfusion after coronary artery bypass surgery. Ann Thorac Surg 2002; 73: 138-42.

99. Sreeram GM, Welsby IJ, Sharma AD, Phillips-Bute B, Smith PK, Slaughter TF. Infectious complications after cardiac surgery: lack of association with fresh frozen plasma or platelet transfusions. J Cardiothorac Vasc Anesth 2005; 19: 430-4.

100. Koch CG, Li L, Duncan AI, Mihaljevic T, Cosgrove DM, Loop FD, et al. Morbidity and mortality risk associated with red blood cell and blood-component transfusion in isolated coronary artery bypass grafting. Crit Care Med 2006; 34: 1608-16.

101. Murphy GJ, Reeves BC, Rogers CA, Rizvi SI, Culliford L, Angelini GD. Increased mortality, postoperative morbidity, and cost after red blood cell transfusion in patients having cardiac surgery. Circulation 2007; 116: 2544-52.

102. Fung MK, Grossman BJ, Hillyer CD, Westhoff CM. Technical Manual. 18th ed. Bethesda, AABB Press. 2014, pp 547-8.

103. Davenport R, Manson J, De'Ath H, Platton S, Coates A, Allard S, et al. Functional definition and characterization of acute traumatic coagulopathy. Crit Care Med 2011; 39: 2652-8.

104. McCrath DJ, Cerboni E, Frumento RJ, Hirsh AL, Bennett-Guerrero E. Thromboelastography maximum amplitude predicts postoperative thrombotic complications including myocardial infarction. Anesth Analg 2005; 100: 1576-83.

105. Leemann H, Lustenberger T, Talving P, Kobayashi L, Bukur M, Brenni M, et al. The role of rotation thromboelastometry in early prediction of massive transfusion. J Trauma 2010; 69: 1403-8.

106. Görlinger K, Dirkmann D, Hanke AA, Kamler M, Kottenberg E, Thielmann M, et al. First-line therapy with coagulation factor concentrates combined with point-of-care coagulation testing is associated with decreased allogeneic blood transfusion in cardiovascular surgery: a retrospective, single-center cohort study. Anesthesiology 2011; 115: 1179-91.

107. Da Luz LT, Nascimento B, Shankarakutty AK, Rizoli S, Adhikari NK. Effect of thromboelastography (TEG $\left.{ }^{\circledR}\right)$ and rotational thromboelastometry $\left(\mathrm{ROTEM}^{\circledR}\right)$ on diagnosis of coagulopathy, transfusion guidance and mortality in trauma: descriptive systematic review. Crit Care 2014; 18: 518.

108. Hunt H, Stanworth S, Curry N, Woolley T, Cooper C, Ukoumunne O, et al. Thromboelastography (TEG) and rotational 
thromboelastometry (ROTEM) for trauma induced coagulopathy in adult trauma patients with bleeding. Cochrane Database Syst Rev 2015; (2): CD010438.

109. Holcomb JB, Minei KM, Scerbo ML, Radwan ZA, Wade CE, Kozar RA, et al. Admission rapid thrombelastography can replace conventional coagulation tests in the emergency department: experience with 1974 consecutive trauma patients. Ann Surg 2012; 256: 476-86.

110. Gauss T, Hamada S, Jurcisin I, Dahmani S, Boudaoud L, Mantz J, et al. Limits of agreement between measures obtained from standard laboratory and the point-of-care device Hemochron Signature Elite(R) during acute haemorrhage. Br J Anaesth 2014; 112: 514-20.

111. Solomon C, Traintinger S, Ziegler B, Hanke A, Rahe-Meyer N, Voelckel W, et al. Platelet function following trauma. A multiple electrode aggregometry study. Thromb Haemost 2011; 106: 322-30. 


\section{Appendix 1. 진료지침 검색전략 및 선별}

\section{가. 검색전략 및 결과}

1) PubMed (Medline)

\begin{tabular}{|c|c|c|c|}
\hline 구분 & $\mathrm{N}$ & 검색어 & 검색결과 \\
\hline \multirow[t]{3}{*}{$\mathrm{P}$} & \#1 & 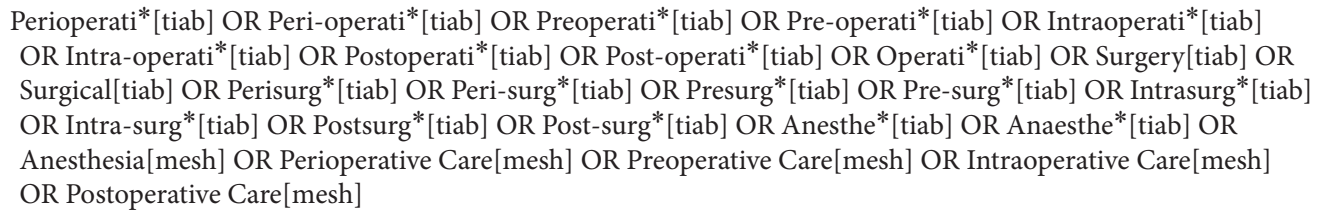 & $2,663,766$ \\
\hline & $\# 2$ & $\begin{array}{l}\text { Erythrocytes[mesh] OR Erythrocyte* }\left[\text { tiab] OR Red Blood Cell* }{ }^{*}[\text { tiab] OR Red Cell* }[\text { tiab] OR RBC* }[\text { tiab] OR }\right. \\
\text { pRBC* }\left[\text { tiab] OR Packed Red Blood Cell*[tiab] OR Packed Red Cell* }{ }^{*} \text { tiab] OR Packed RBC }[\text { tiab] OR Blood }\right. \\
\text { Component }^{*}[\text { tiab] }\end{array}$ & 290,846 \\
\hline & $\# 3$ & $\# 1 \mathrm{OR} \# 2$ & $2,937,583$ \\
\hline I & $\# 4$ & Blood Transfusion[mesh] OR Blood Transfusion*[tiab] OR Transfusion*[tiab] OR Blood Management*[tiab] & 139,737 \\
\hline P\&I & \#5 & $\# 3 \mathrm{AND} \# 4$ & 57,806 \\
\hline 포함기준 & $\# 6$ & $\begin{array}{l}\text { Guideline*[tiab] OR Practice Guideline*[tiab] OR Clinical Practice Guideline*[tiab] OR Clinical } \\
\text { Guideline* }[\text { tiab] OR Guideline[publication type] OR Practice Guideline[publication type] }\end{array}$ & 304,692 \\
\hline 종합 & \#7 & \#5 AND \#6 & 2,073 \\
\hline 제한 & & Limit $2010.01 .01-2017.12 .31$ & 1,111 \\
\hline
\end{tabular}

\section{2) EMBASE}

\begin{tabular}{|c|c|c|c|}
\hline 구분 & $\mathrm{N}$ & 검색어 & 검색결과 \\
\hline \multirow[t]{3}{*}{$\mathrm{P}$} & $\# 1$ & 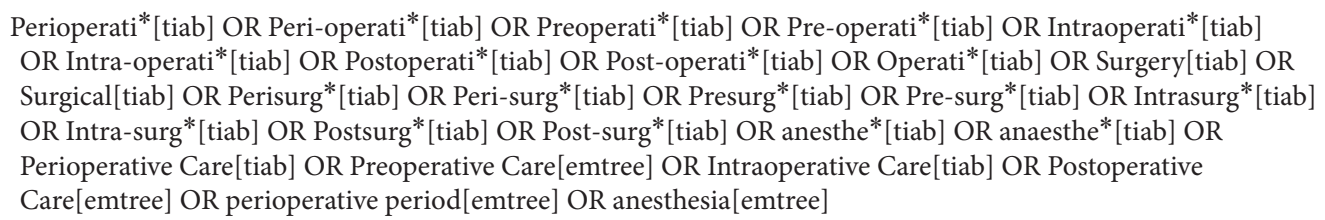 & $3,435,616$ \\
\hline & $\# 2$ & 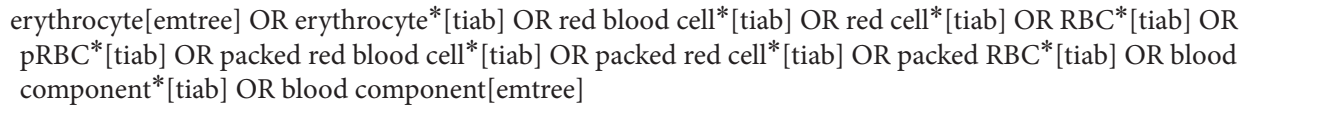 & 331,510 \\
\hline & $\# 3$ & $\# 1 \mathrm{OR} \# 2$ & $3,740,720$ \\
\hline I & $\# 4$ & $\begin{array}{l}\text { blood transfusion[emtree] OR blood transfusion*[tiab] OR transfusion*[tiab] OR transfusion[emtree] OR blood } \\
\text { management* }[\text { tiab] }\end{array}$ & 337,643 \\
\hline P\&I & $\# 5$ & $\# 3 \mathrm{AND} \# 4$ & 112,970 \\
\hline 포함기준 & \#6 & $\begin{array}{l}\text { Guideline*[tiab] OR Practice Guideline*[tiab] OR Clinical Practice Guideline*[tiab] OR Clinical Guideline*[tiab] } \\
\text { OR practice guideline[emtree] }\end{array}$ & 718,694 \\
\hline 종합 & \#7 & $\# 5$ AND \#6 & 7,147 \\
\hline 제한 & & Limit 2010.01.01-2017.12.31 & 2,156 \\
\hline
\end{tabular}


3) Cochrane Library

\begin{tabular}{|c|c|c|c|}
\hline 구분 & $\mathrm{N}$ & 검색어 & 검색결과 \\
\hline \multirow[t]{3}{*}{$\mathrm{P}$} & $\# 1$ & $\begin{array}{l}\text { Perioperati*:ti,ab,kw OR Peri-operati*:ti,ab,kw OR Preoperati*:ti,ab,kw OR Pre-operati*:ti,ab,kw OR } \\
\text { Intraoperati*:ti,ab,kw OR Intra-operati*:ti,ab,kw OR Postoperati*:ti,ab,kw OR Post-operati*:ti,ab,kw OR } \\
\text { Operati*:ti,ab,kw OR Surgery:ti,ab,kw OR Surgical:ti,ab,kw OR Perisurg*:ti,ab,kw OR Peri-surg*:ti,ab,kw OR } \\
\text { Presurg*:ti,ab,kw OR Pre-surg*:ti,ab,kw OR Intrasurg*:ti,ab,kw OR Intra-surg*:ti,ab,kw OR Postsurg*:ti,ab,kw } \\
\text { OR Post-surg*:ti,ab,kw OR Anesthe*ti,ab,kw OR Anaesthe*:ti,ab,kw OR MeSH descriptor: [Perioperative Care] } \\
\text { OR MeSH descriptor: [Preoperative Care] OR MeSH descriptor: [Intraoperative Care] OR MeSH descriptor: } \\
\text { [Postoperative Care] OR MeSH descriptor: [Anesthesia] }\end{array}$ & 2,354 \\
\hline & $\# 2$ & $\begin{array}{l}\text { MeSH descriptor: [Erythrocytes] OR Erythrocyte*:ti,ab,kw OR Red Blood Cell*:ti,ab,kw OR Red Cell*:ti,ab,kw OR } \\
\text { RBC*:ti,ab,kw OR pRBC*:ti,ab,kw OR Packed Red Blood Cell*:ti,ab,kw OR Packed Red Cell*:ti,ab,kw OR Packed } \\
\text { RBC* }^{*} \text { ti,ab,kw OR Blood Component*:ti,ab,kw }\end{array}$ & 265 \\
\hline & $\# 3$ & $\# 1 \mathrm{OR} \# 2$ & 2,556 \\
\hline I & $\# 4$ & $\begin{array}{l}\text { MeSH descriptor: [Blood Transfusion] OR Blood Transfusion*:ti,ab,kw OR Transfusion*:ti,ab,kw OR Blood } \\
\text { Management*:ti,ab,kw }\end{array}$ & 598 \\
\hline P\&I & $\# 5$ & $\# 3$ AND \#4 & 322 \\
\hline 포함기준 & \#6 & $\begin{array}{l}\text { Guideline*:ti,ab,kw OR Practice Guideline*:ti,ab,kw OR Clinical Practice Guideline*:ti,ab,kw OR Clinical } \\
\text { Guideline*:ti,ab,kw OR Guideline:pt OR Practice Guideline:pt }\end{array}$ & 592 \\
\hline 종합 & $\# 7$ & $\# 5$ AND \#6 & 23 \\
\hline 제한 & & Limit 2010.01.01-2017.12.31 & 21 \\
\hline
\end{tabular}

4) KoreaMed

\begin{tabular}{|c|c|c|c|}
\hline 구분 & $\mathrm{N}$ & 검색어 & 검색결과 \\
\hline \multirow[t]{3}{*}{$\mathrm{P}$} & $\# 1$ & $\begin{array}{l}\text { Perioperati* }[\mathrm{TI}] \text { OR Perioperati* }[\mathrm{AB}] \text { OR Peri-operati* [TI] OR Peri-operati* [AB] OR Preoperati* [TI] OR } \\
\text { Preoperati* }[\mathrm{AB}] \text { OR Pre-operati* [TI] OR Pre-operati* [AB] OR Intraoperati* [TI] OR Intraoperati* [AB] OR } \\
\text { Intra-operati* [TI] OR Intra-operati* [AB] OR Postoperati* [TI] OR Postoperati* [AB] OR Post-operati* [TI] } \\
\text { OR Post-operati* [AB] OR Operati* [TI] OR Operati* [AB] OR Surgery [TI] OR Surgery [AB] OR Surgical [TI] } \\
\text { OR Surgical [AB] OR Perisurg* [TI] OR Perisurg*[AB] OR Peri-surg* [TI] OR Peri-surg* [AB] OR Presurg* } \\
\text { [TI] OR Presurg* [AB] OR Pre-surg* [TI] OR Pre-surg* [AB] OR Intrasurg* [TI] OR Intrasurg* [AB] OR Intra- } \\
\text { surg* [TI] OR Intra-surg* [AB] OR Postsurg* [TI] OR Postsurg* [AB] OR Post-surg* [TI] OR Post-surg* [AB] } \\
\text { OR Anesthe* [TI] OR Anesthe*[AB] OR Anaesthe*[TI] OR Anaesthe*[AB] }\end{array}$ & 68,145 \\
\hline & $\# 2$ & 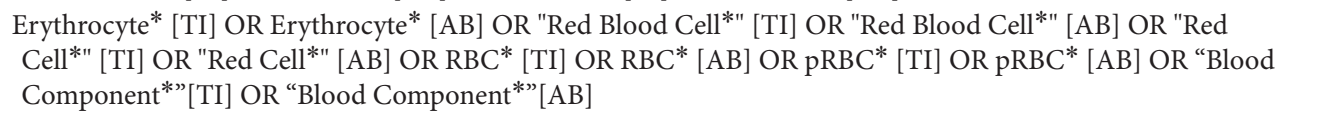 & 2,272 \\
\hline & $\# 3$ & $\# 1 \mathrm{OR} \# 2$ & 69,989 \\
\hline I & $\# 4$ & Transfusion* [TI] OR Transfusion* [AB] OR "Blood Management*" [TI] OR "Blood Management*" [AB] & 2,298 \\
\hline P\&I & $\# 5$ & $\# 3 \mathrm{AND} \# 4$ & 1,521 \\
\hline 포함기준 & $\# 6$ & $\begin{array}{l}\left.\text { Guideline* }^{*} \mathrm{TI}\right] \text { OR Guideline* }[\mathrm{AB}] \text { OR "Practice Guideline*" [TI] OR "Practice Guideline*" }[\mathrm{AB}] \text { OR "Clinical } \\
\text { Practice Guideline*" [TI] OR "Clinical Practice Guideline*" [AB] }\end{array}$ & 4,402 \\
\hline 종합 & $\# 7$ & $\# 5$ AND \#6 & 66 \\
\hline 제한 & & Limit 2010.01.01-2017.12.31 & 27 \\
\hline
\end{tabular}


5) KMbase

\begin{tabular}{|c|c|c|c|}
\hline 구분 & $\mathrm{N}$ & 검색어 & 검색결과 \\
\hline \multirow[t]{3}{*}{$\mathrm{P}$} & $\# 1$ & $\begin{array}{l}\text { [TITLE=Perioperati*] OR [ABSTRACT=Perioperati*] OR [TITLE=Preoperati*] OR [ABSTRACT=Preoperati*] } \\
\text { OR [TITLE=Intraoperati*] OR [ABSTRACT=Intraoperati*] OR [TITLE=Postoperati*] OR } \\
\text { [ABSTRACT=Postoperati*] OR [TITLE=Operati*] OR [ABSTRACT=Operati*] OR [TITLE=Surgery] } \\
\text { OR [ABSTRACT=Surgery] OR [TITLE=Surgical] OR [ABSTRACT=Surgical] OR [TITLE=Perisurg*] OR } \\
\text { [ABSTRACT=Perisurg*] OR [TITLE=Peri-surg*] OR [ABSTRACT=Peri-surg*] OR [TITLE=Presurg*] OR } \\
\text { [ABSTRACT=Presurg*] OR [TITLE=Pre-surg*] OR [ABSTRACT=Pre-surg*] OR [TITLE=Intrasurg*] OR } \\
\text { [ABSTRACT=Intrasurg*] OR [TITLE=Intra-surg*] OR [ABSTRACT=Intra-surg*] OR [TITLE=Postsurg*] } \\
\text { OR [ABSTRACT=Postsurg*] OR [TITLE=Post-surg*'] OR [ABSTRACT=Post-surg*] OR [TITLE=주술기] OR } \\
\text { [ABSTRACT=주술기] OR [TITLE=술전] OR [ABSTRACT=술전] OR [TITLE=술전] OR [ABSTRACT=술전] } \\
\text { OR [TITLE=술중] OR [ABSTRACT=술중] OR [TITLE=술중] OR [ABSTRACT=술중] OR [TITLE=술후] OR } \\
\text { [ABSTRACT=술후] OR [TITLE=술후] OR [ABSTRACT=술후] OR [TITLE=수술] OR [ABSTRACT=수술] }\end{array}$ & 88,160 \\
\hline & $\# 2$ & 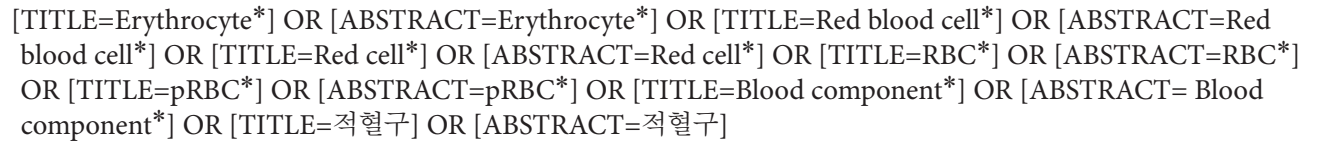 & 5,662 \\
\hline & $\# 3$ & $\# 1 \mathrm{OR} \# 2$ & 93,642 \\
\hline I & $\# 4$ & 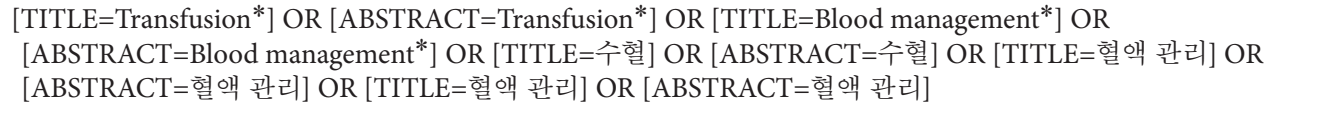 & 3,162 \\
\hline P\&I & $\# 5$ & $\# 3 \mathrm{AND} \# 4$ & 142 \\
\hline 포함기준 & $\# 6$ & $\begin{array}{l}\text { [TITLE=Guideline*] OR [ABSTRACT=Guideline*] OR [TITLE=Practice Guideline*] OR [ABSTRACT=Practice } \\
\text { Guideline* } \text { OR [TITLE=Clinical Practice Guideline*] OR [ABSTRACT=Clinical Practice Guideline*] OR } \\
\text { [TITLE=가이드라인] OR [ABSTRACT=가이드라인] OR [TITLE=지침] OR [ABSTRACT=지침] OR [TITLE=권 } \\
\text { 고안] OR [ABSTRACT=권고안] OR [TITLE=임상시험 관리기준] OR [ABSTRACT=임상시험 관리기준] }\end{array}$ & 8,444 \\
\hline 종합 & $\# 7$ & $\# 5$ AND \#6 & 14 \\
\hline 제한 & & Limit 2010.01.01-2017.12.31 & 4 \\
\hline
\end{tabular}

6) 국내외 검색현황 (2010.01.01-2017.12.31)

\begin{tabular}{|c|c|c|c|}
\hline \multicolumn{4}{|c|}{ Search Results } \\
\hline No & $\mathrm{DB}$ & Results & Duplication \\
\hline 1 & PubMed (Medline) & 1,111 & 975 \\
\hline 2 & EMBASE & 2,156 & \\
\hline 3 & Cochrane Library & 21 & \\
\hline 4 & KoreaMed & 27 & \\
\hline 5 & KMbase & 4 & \\
\hline 6 & G-I-N & 1 & \\
\hline 7 & National Guideline Clearinghouse (AHRQ) & 7 & \\
\hline 8 & National Institute for Health and Care Excellence (NICE) & 1 & \\
\hline 9 & Scottish Intercollegiate Guidelines Network (SIGN) & 1 & \\
\hline 10 & CMA Infobase & 0 & \\
\hline 11 & Guidelines and Audit Implementation Network (GAIN) & 0 & \\
\hline 12 & WHO Guidelines & 0 & \\
\hline 13 & Australian Clinical Practice Guidelines & 0 & \\
\hline 14 & Canadian Clinical Practice Guidelines & 0 & \\
\hline 15 & KoMGI & 0 & \\
\hline & Total & 3,329 & 2,354 \\
\hline
\end{tabular}




\section{나. 흐름도}

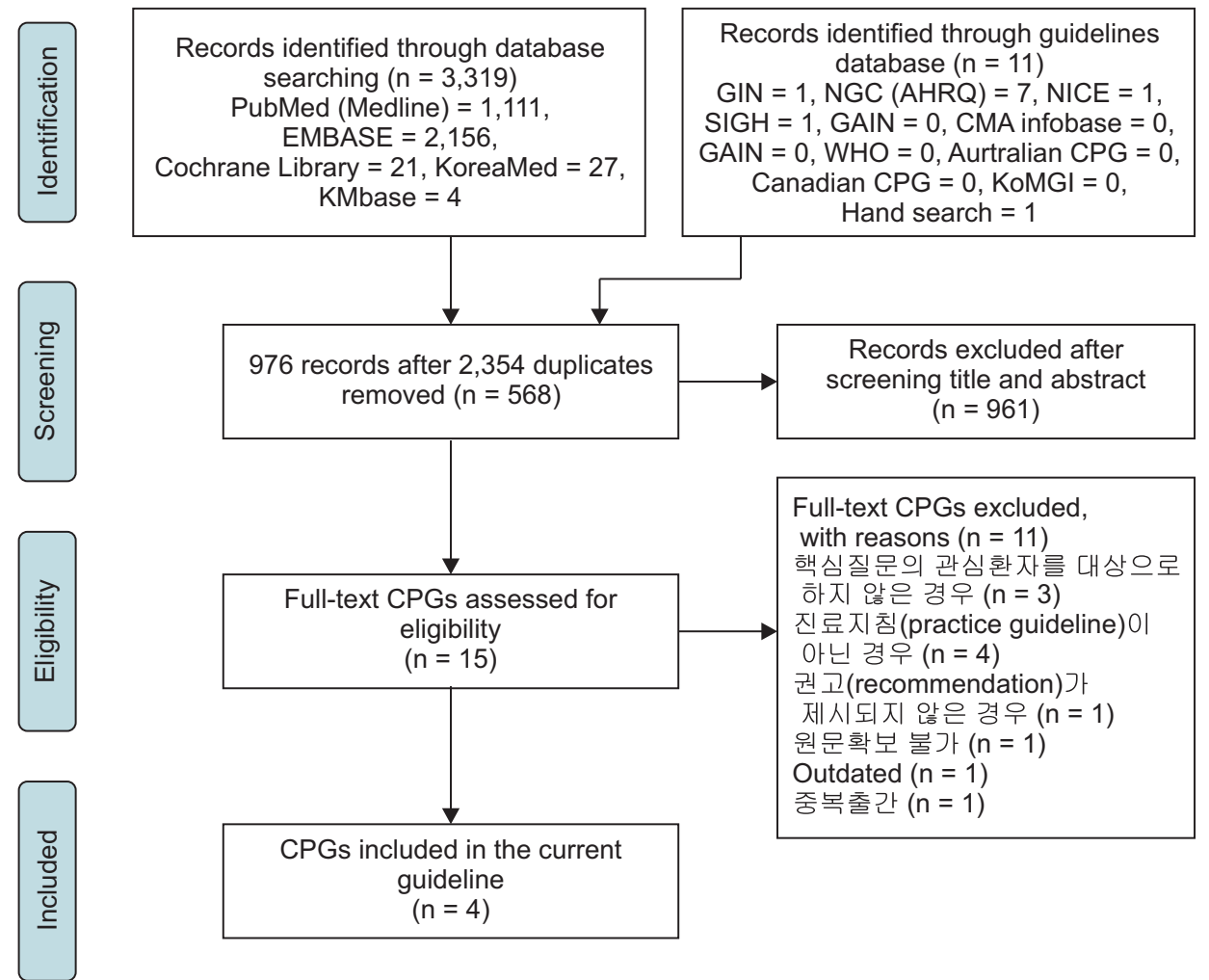

PRISMA 2009 Flow Diagram

\section{다. 배제된 검색 문헌 목록 및 사유}

1) 핵심질문의 관심환자를 대상으로 하지 않은 경우 $(n=3)$

1. Jones H, Reeve K. Transfusion guidelines in children: II. Anaesth Intensive Care Med 2017; 18: 546-50.

2. Watson S, Kendrick K. Management of anaemia and blood transfusion in critical care - implementing national guidelines in ICU. BMJ Qual Improv Rep 2014; 3.

3. Westbrook A, Pettila V, Nichol A, Bailey MJ, Syres G, Murray L, et al. Transfusion practice and guidelines in Australian and New Zealand intensive care units. Intensive Care Med 2010; 36: 1138-46.

2) 진료지침(Practice Guideline)이 아닌 경우 $(n=4)$

1. Tobian AA, Heddle NM, Wiegmann TL, Carson JL. Red blood cell transfusion: 2016 clinical practice guidelines from AABB. Transfusion 2016; 56: 2627-30.

2. Blood transfusion: Quality standard [Internet]. London: National Institute for Health and Care Excellence (NICE); 2016 Dec 15 [cited 2018 Nov 19]. Available from https://www.nice.org.uk/guidance/qs138/resources/blood-transfusion-pdf-75545425760965.

3. Carson JL, Stanworth SJ, Roubinian N, Fergusson DA, Triulzi D, Doree C, et al. Transfusion thresholds and other strategies for guiding allogeneic red blood cell transfusion. Cochrane Database Syst Rev 2016; 10: CD002042.

4. Dietrich W, Faraoni D, von Heymann C, Bolliger D, Ranucci M, Sander M, et al. ESA guidelines on the management of severe perioperative bleeding: comments on behalf of the Subcommittee on Transfusion and Haemostasis of the European Association 
of Cardiothoracic Anaesthesiologists. Eur J Anaesthesiol 2014; 31: 239-41.

3) 권고(recommendation)가 제시되지 않은 경우 $(\mathrm{n}=1)$

1. Blood transfusion: NICE guideline [Internet]. National Institute for Health and Care Excellence (NICE); 2015 Nov 18 [cited 2018 Nov 19]. Available from https://www.nice.org.uk/guidance/ng24/resources/blood-transfusion-1837331897029.

4) 원문확보 불가 $(n=1)$

1. Morrison A. Perioperative blood transfusion. Edinburgh, Scottish Intercollegiate Guidelines Network. 2016.

5) Outdated $(n=1)$

1. Carson JL, Grossman BJ, Kleinman S, Tinmouth AT, Marques MB, Fung MK, et al. Red blood cell transfusion: a clinical practice guideline from the AABB*. Ann Intern Med 2012; 157: 49-58.

6) 중복출간 $(n=1)$

1. National Guideline Clearinghouse. Practice guidelines for perioperative blood management: an updated report by the American Society of Anesthesiologists Task Force on Perioperative Blood Management. Rockville MD, Agency for Healthcare Research and Quality. 2015. Available from https://www.ahrq.gov. 


\section{Appendix 2. 임상진료지침 평가(K-AGREE II에 의한 표준화 점수)}

\begin{tabular}{|c|c|c|c|c|c|c|c|}
\hline 진료지침 & 년도 & 범위와 목적 & 이해당사자의 참여 & 계발의 엄격성 & 표현의 명확성 & 적용성 & 편집의 독립성 \\
\hline ASA & 2015 & 6.0 & 5.4 & 5.6 & 5.5 & 3.3 & 5.6 \\
\hline AAGBI & 2016 & 4.8 & 2.9 & 2.7 & 5.8 & 2.9 & 5.8 \\
\hline $\mathrm{AABB}$ & 2016 & 6.6 & 5.6 & 5.6 & 5.7 & 3.6 & 6.0 \\
\hline 질병관리본부 & 2016 & 5.9 & 4.0 & 2.8 & 4.3 & 5.5 & 2.2 \\
\hline
\end{tabular}

K-AGREE II: Korean version of the Appraisal of Guidelines for Research and Evaluation II, ASA: American Society of Anesthesiologists, AAGBI: Association of Anaesthetists of Great Britain and Ireland, AABB: American Association of Blood Banks. 